\title{
Planejamento público e gerenciamento de crises na pandemia da Covid-19 em destinos turísticos no Brasil: Ações sustentáveis ou reações econômicas?
}

\author{
Public planning and crisis management in the Covid-19 pandemic in Brazilian \\ tourist destinations: Sustainable actions or economic reactions?
}

\author{
Elias José Mediotte \\ Universidade Federal de Viçosa, Brasil \\ eliasmediotte@gmail.com \\ Magnus Luiz Emmendoerfer \\ Universidade Federal de Viçosa, Brasil \\ magnus@ufv.br \\ Yuri Tomaz dos Santos \\ Universidade Federal de Viçosa, Brasil \\ magnus@ufv.br \\ Brendow de Oliveira Fraga \\ Universidade Federal de Viçosa, Brasil \\ brendowfraga@gmail.com
}

\begin{abstract}
Resumo
O impacto causado pela crise epidemiológica da Covid-19 nos municípios turísticos brasileiros exige da governança local a implementação de ações de enfrentamento e gerenciamento da crise convulsionada pela suspensão das atividades do trade turístico. Assim sendo, e considerando a limitação de estudos teóricos e empíricos no âmbito da gestão de pandemias em destinos turísticos que articulem planejamento, gerenciamento de crises e governança, objetiva-se nesse trabalho apontar quais medidas são adotadas, em nível local, para o enfrentamento da pandemia causada pela Covid-19, no município de Tiradentes (Minas Gerais), tendo de um lado a possibilidade de reabertura e flexibilização das atividades econômicas e, de outro, as recomendações pelo isolamento social. A análise documental e de conteúdo possibilitaram considerar Tiradentes um município de governança atomizada, identificando priorização da dimensão econômica em desconformidade com os aspectos socioambientais e socioculturais e ausência de um planejamento que vise a recuperação dos impactos da Covid-19 no cenário pós-pandemia.
\end{abstract}

Palavras-chave: gerenciamento de crises; planejamento público sustentável; governança turística; destinos turísticos; pandemia da Covid-19.

Dos Algarves: A Multidisciplinary e-Journal, 40-2021.

ISBN 2182-5580 @ ESGHT - University of the Algarve, Portugal.

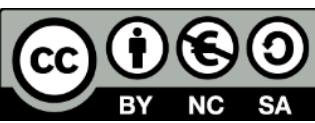

To cite this article: Mediotte, E.J., Emmendoerfer, M.L., Santos, Y.T. \& Fraga, B. O. (2021). Planejamento público e gerenciamento de crises na pandemia da Covid-19 em destinos turísticos no Brasil: Ações sustentáveis ou reações econômicas? Dos Algarves: A Multidisciplinary e-Journal, 40, 1-30. DOI: 10.18089/DAMeJ.2021.40.1 


\begin{abstract}
The impact caused by the public health crisis of the Covid-19 in Brazilian tourist cities demands that local governance implements actions to respond to and manage the crisis resulting from the suspension of tourist activities. The objective of this paper is to highlight which measures are being adopted, at a local level, in the historic and tourist city of Tiradentes in Minas Gerais State, whilst considering the limitations of theoretical and empirical studies which articulate planning, crisis management and governance in the scope of the pandemic management in tourist destinations. On the one hand, tourist destinations have the possibility of reopening and flexibilization of economic activities and on the other, the social distancing recommendations. The documental and content analysis carried out made it possible to consider Tiradentes a city of atomized governance. As a result, we identified the prioritization of the economic dimension out of conformity with the socio-environmental and socio-cultural aspects and the lack of a planning that aims to recover from the impacts of Covid-19 in the post-pandemic scenario.
\end{abstract}

Keywords: crisis management; sustainable public planning; tourist governance; tourist destinations; Covid-19 pandemic.

\title{
1. Introdução
}

Devido à recessão global da pandemia causada pelo novo Coronavírus (Covid-19), originalmente identificado na China, em dezembro de 2019 (Flaxman et al., 2020), vivencia-se a pior crise econômica, desde a Segunda Guerra Mundial (World Bank, 2020). No contexto do turismo, a Organização Mundial do Turismo (OMT) declarou que a movimentação de turistas internacionais obteve uma queda de $72 \%$, podendo chegar a $75 \%$, o que representa a perda de mais de 1 bilhão de turistas, o equivalente à soma de US\$ 1,1 trilhão. Ademais, destaca sobre a perda estimada no PIB global superior a US\$2 trilhões, além do risco de desemprego alcançar a margem de 100 a 120 milhões trabalhadores (UNWTO, 2020a). A OMT reconhece que a baixa confiança dos turistas e as medidas de enfrentamento para combater a pandemia causada pela Covid-19 classificaram 2020 como "o pior ano já registrado na história do turismo" (UNWTO, 2020b: 1).

No Brasil e nos demais países considerados indutores e fomentadores de turismo 'staycations' e internacional, tal impacto tem causado efeitos devastadores nos destinos turísticos, sobretudo nos municípios em que o turismo representa exclusiva atividade econômica (Niestadt, 2020). Consequentemente, esse cenário tem exigido da governança local um gerenciamento de crises alinhado a um planejamento público que se mostre sustentável, visando o enfrentamento atual da pandemia e a recuperação dos efeitos causados pela Covid-19, no cenário pós-pandemia. Tal argumento reitera o estímulo a políticas públicas de engajamento dos atores sociais (gestão pública, iniciativa privada e comunidade civil local), em convergência com as esferas socioeconômicas, socioculturais, socioambientais, éticas e políticas, visando o desenvolvimento sustentável do turismo (Trentin, 2016).

Tendo em vista a paralisação de toda a indústria do turismo, em decorrência da pandemia da Covid-19, medidas de isolamento social, fechamento das atividades consideradas não essenciais, em especial o trade turístico, o cancelamento e adiamento de 
viagens, a suspensão de eventos e barreiras sanitárias tornaram-se realidade na vida dos destinos turísticos brasileiros. De um lado, há o apelo econômico para reabertura do trade e flexibilização das fronteiras; e, de outro, as orientações dos órgãos de saúde para a manutenção do distanciamento social e suspensão das atividades econômicas não essenciais. Ademais, a literatura mostra-se limitada acerca de estudos que abarquem, empiricamente, tal cenário, bem como no que concerne às medidas adotadas por destinos turísticos no Brasil para o enfrentamento de crises epidemiológicas, por meio de um gerenciamento de crises e planejamento público sustentável, durante e pós-pandemia.

Nesse sentido, este estudo busca responder à seguinte questão norteadora: quais medidas têm sido adotadas para o enfrentamento da pandemia causada pela Covid-19 em um destino exclusivamente turístico, no Brasil, tendo de um lado, a possibilidade de reabertura e flexibilização das atividades econômicas e, de outro, as recomendações pelo isolamento social? Para responder a esta questão, tem-se como objetivo central evidenciar o envolvimento da governança turística local na implementação de ações de enfrentamento da crise epidemiológica, tendo em vista o período de suspensão das suas principais atividades e como tem ocorrido o planejamento do desenvolvimento do turismo para o cenário póspandemia.

O município de Tiradentes foi selecionado como caso de estudo, pois, além de ter obtido a máxima condecoração (conceito A) do MTur nos anos de 2017-2019, numa escala entre A, B, C, D, E (cf. Brasil, MTur, 2019), esteve entre os 4 municípios turísticos de Minas Gerais na política nacional dos '65 Destinos Indutores no Brasil' (cf. Brasil, MTur, 2015). Dentre eles, Tiradentes é o município cuja atividade turística é a sua principal (e exclusiva) atividade econômica (SENAC, 2020).

Dois elementos-chaves configuram-se importantes para o alcance do objetivo proposto, os quais são objetos de análise e execução deste estudo: o planejamento público e a (re)adaptação de um modus de gerenciamento de crises (Gladu, 2003), em nível local. Tal proposta é considerada inovadora, pois permite analisar o cenário de pandemia, aplicando um modus de gerenciamento de crises, ressignificado para um município exclusivamente turístico.

\section{Planejamento público no turismo e o gerenciamento de crises}

No contexto do turismo, concebe-se sobre planejamento sustentável o dispositivo que antecede a ocorrência de fenômenos que podem ser previstos, servindo como uma ferramenta norteadora para atividades concernentes às autoridades de governos, priorizando, para além da dimensão socioeconômica, os aspectos socioculturais e socioambientais (Inskeep, 1993; Ruschmann, 1997). O planejamento público é uma deliberação e subcategoria indissociável da governança, uma vez que esse tipo de gestão democrática e participativa pressupõe a inclusão da sociedade civil e atores públicos e privados na formulação, implementação, fiscalização e orientação de políticas públicas (Dallabrida, 2016).

A colaboração entre os stakeholders que compõem a governança, bem como a efetiva atuação dos parceiros nas etapas do planejamento, é oriunda do compartilhamento de 
poder, que se contrapõe às tomadas de decisões de modo monocrático. A tríade agentes do setor público, privado e sociedade civil, é o arranjo de representantes capazes de suscitar a sustentabilidade a partir da alocação dos moradores locais nos processos decisórios, parcerias e exercício responsável dos papéis que desempenham na rede (Dallabrida, 2016). Com base nessa articulação harmonica, são fomentadas políticas públicas, a fim de potencializar o local de acordo com suas particularidades socioeconômicas, socioambientais e socioculturais (Santos \& Pereira, 2020).

A sustentabilidade é um termo recorrente e presente nas discussões e estudos acerca do planejamento e da governança no turismo (Mediotte, 2020). Especificamente em nível global, o termo sustentável tem sido evidenciado e fomentado pela Organização das Nações Unidas (ONU, 2016), visando assegurar direitos, deveres e oportunidades fundamentados na igualdade e equidade, além de promover a conservação dos insumos provenientes do desenvolvimento e da (re)transformação de territórios. Nesse sentido, destaca-se a Agenda 2030 concebida em 2015, congregando 17 Objetivos de Desenvolvimento Sustentável (ODS) (Tabela 1) e 169 metas instituídas entre 193 países comprometidos em melhorar a qualidade de vida dos cidadãos, sobretudo das famílias em situações socioeconômicas vulneráveis.

Tabela 1. Objetivos de Desenvolvimento Sustentável (ODS): Agenda 2030

\begin{tabular}{|c|l|c|l|}
\hline ODS N & \multicolumn{1}{|c|}{ Objetivo } & ODS N & \multicolumn{1}{|c|}{ Objetivo } \\
\hline 1 & Erradicação da pobreza & 2 & Fome zero e agricultura sustentável \\
\hline 3 & Saúde e bem-estar & 4 & Educação de qualidade \\
\hline $\mathbf{5}$ & Igualdade de gênero & 6 & Água potável e saneamento \\
\hline 7 & Energia limpa e acessível & $\mathbf{8}$ & Trabalho descente e crescimento econômico \\
\hline $\mathbf{9}$ & Indústria, inovação e infraestrutura & 10 & Redução das desigualdades \\
\hline $\mathbf{1 1}$ & Cidades e comunidades sustentáveis & 12 & Consumo e produção responsáveis \\
\hline 13 & Ação controlada a mudança global do clima & 14 & Vida na água \\
\hline 15 & Vida terrestre & 16 & Paz, justiça e instituições eficazes \\
\hline 17 & Parcerias e meios de implementação & & \multicolumn{2}{|l}{} \\
\hline
\end{tabular}

Fonte: Elaboração própria com base em ONU (2016).

O planejamento público sustentável está diretamente ligado à antecedência do irrompimento de crises e emergências. Para o setor público, a gestão de crises no contexto do turismo exige o cumprimento de respostas à ação e à organização dos líderes governamentais e dos grupos de interesse, para reagirem aos fenômenos por meio de planejamento com enfoque na sustentabilidade. O gerenciamento de crises, embora seja um campo de estudos limitado e ainda emergente (Paraskevas et al., 2013), é um processo dinâmico e indissociável da coordenação e colaboração dos stakeholders, devendo ser bem articulado e responsivo, no que diz respeito à atuação e papel dos atores envolvidos. A crise diz respeito a uma condição em que os problemas "não representam necessariamente uma 
séria ameaça à vida ou à propriedade humana" e as consequências podem ser previstas (Gladu, 2003: 4).

Para a composição da governança de um município turístico, o planejamento sustentável não se refere às implicações que o crescimento econômico representa, em detrimento das demais dimensões, mas sim, sobre o desenvolvimento equitativo das dimensões socioculturais socioambientais, políticas e éticas em consonância com o socioeconômico. Portanto, confere-se sobre sustentabilidade a harmonização da tríade supradita no que concerne ao desenvolvimento e a priorização desta no planejamento de gestão de crises por autoridades de governos, excepcionalmente com enfoque no contexto local.

Uma crise exige um planejamento que abarque a prevenção e a proposição de tratamento do fenômeno eclodido, seja em locais, municípios, instituições, contexto político e sanitário etc., uma vez que são várias as possibilidades: desastres ambientais, surtos epidemiológicos, acidentes, terrorismo e ataques cibernéticos. Além do mais, pressupõe-se que a governança seja composta, a nível institucional, local, estadual e nacional, por representantes plurais e experts de diversos campos de saberes (Gladu, 2003).

Tendo em vista o contexto deste estudo, a literatura sobre crises epidemiológicas que abarca a gestão pública e os impactos no turismo, pode-se citar como exemplo o surto epidêmico da Síndrome Respiratória Aguda Grave (SARS), que devastou o turismo asiático entre os anos de 2002 e 2003 (Lam et al., 2003; McKercher \& Chon, 2004; Wilder-Smith, 2006), principalmente na China, Hong Kong, Cingapura e Vietnã. Além de ter causado uma perda de US\$ 20 bilhões no PIB destes territórios, o turismo apresentou uma queda de aproximadamente $70 \%$ entre as viagens e movimentação de turistas para todo o continente asiático, inclusive às nações não afetadas pelo surto do SARS-Cov-1 (Coronavírus), ao redor do mundo. Medidas restritivas foram tomadas em diversos países como Tailândia, Canadá, Vietnã, Cingapura, China, Hong Kong, Taiwan, entre outros, a partir do 'aviso geral de viagens' da OMS, desencadeando uma célere cadeia de respostas quanto ao risco de tornarse uma pandemia (Lam et al., 2003). Pode-se inferir que o SARS representou a confirmação de que o turismo possui uma "ligação explícita entre as viagens e a disseminação global de uma doença" (McKercher \& Chon, 2004: 716).

Embora tenha havido ações estratégicas para a contenção imediata do SARS a partir do desenvolvimento de soluções, os contextos históricos sobre crises epidemiológicas (Cooper, 2008; Kuo et al., 2008) fazem emergir a necessidade e a importância da governança sob a ótica da cooperação, coordenação e colaboração entre os setores que representam o sistema turístico. Isto posto, compreende-se que em situações nas quais não há um gerenciamento de crises com enfoque no planejamento público e na sustentabilidade, mesmo as ações eficazes mais simples e secundárias não são suficientes para conter o pânico de novas doenças, suas origens, transmissibilidades e tratamentos, sobretudo quando há uma ausência de parcerias transfronteiriças e equívocos dos governos, mesmo os mais bem intencionados, no combate e enfrentamento de crises sanitárias. Endossam esses argumentos, os colapsos aos fluxos turísticos atribuídos à reação inapta da gestão pública às 
ameaças de perigo iminente (Paraskevas et al., 2013), cujas desinformações se propagam mais rápido do que as doenças (McKercher \& Chon, 2004; Wilder-Smith, 2006).

O gerenciamento de crises no Serviço Público (Gladu, 2003) envolve quatro fases de ações: a) Mitigação; b) Preparação; c) Resposta; e d) Recuperação. A fase de mitigação considera ações que são necessárias para a redução dos efeitos causados pela crise, incluindo recuo aos fenômenos semelhantes ocorridos anteriormente, a fim de analisar os planos de ações para minimizar os impactos, bem como o escalonamento de especialistas para cada contexto. A fase de preparação é o momento em que o planejamento, diante da crise, será implementado, ou seja, um "um plano operacional” (Gladu, 2003: 10) com enfoque em treinamento dos sujeitos de acordo com as funções atribuídas a eles, procedimentos administrativos, grupo de liderança que comissionará os demais membros, mensuração de logística para aquisição de equipamentos informáticos e de natureza comunicacional, equipe de suporte técnico, entre outros. Tendo em vista a organização das ações necessárias da preparação, essa é uma das fases mais demoradas, pois “os planos precisam ser testados periodicamente e a equipe de resposta e seu pessoal de suporte precisam receber treinamento apropriado" (Gladu, 2003: 11).

A terceira fase é a aplicabilidade da fase de preparação, em que todos os planos dispostos no planejamento serão finalmente ativados e executados. Portanto, a fase de resposta exige preparação da comissão que atuará no gerenciamento, uma vez que os líderes da comissão se reúnem para instruir os membros de seus papéis, orientando a equipe de comunicação para divulgar e atualizar as informações perante a mídia. Por fim, a fase de recuperação, que é de natureza consultiva, verifica os impactos causados pela crise após a declaração oficial de seu fim, quais constructos podem ser depreendidos a partir das experiências, induzindo novos planejamentos e constantes contatos com a mídia e organizações parceiras (Gladu, 2003).

A eclosão de uma crise pode ser influenciada por lideranças, isto é, de comandos e prospecção da gestão central, o que permite inferir que tais situações são oriundas da ineficiência ou má elaboração do planejamento que deveria antever as possibilidades não conjecturadas (Paraskevas et al., 2013). Ao mesmo tempo, as respostas às crises ou emergências são provenientes da articulação dos atores com compõem a governança. A inércia diante dos acontecimentos, a insuficiência no modo de articulação e atuação efetiva podem ser reflexos da ausência de indicadores que caracterizam a governança (cf. Mediotte, 2020).

Paraskevas et al. (2013) reforçam que o desenvolvimento de crises seria a potencialização dela a partir das incompetências administrativas, isto é, dos gestores responsáveis, por minimizá-las, e pela impossibilidade de enxergarem em experiências anteriores, aprendizados que poderiam ser percebidos a depender das prioridades e nível de afetação da eficiência do planejamento, revisão e omissão das falhas.

\section{Procedimentos metodológicos}

Trata-se de um estudo de caso: o município de Tiradentes, no estado de Minas Gerais (MG), Brasil. Considerando o atual contexto deste estudo, utilizou-se, também, uma análise descritiva a fim de complementar os procedimentos adotados, pois acredita-se que 
investigações com auxílio dessa perspectiva possibilitam uma observação mais próxima da realidade identificada empiricamente, conjugada à concepção epistemológica entre a dimensão teórica com o processo indutivo (Minayo, 2011; Triviños, 1987).

A partir da Revisão de Literatura traçou-se os seguintes pressupostos: 1. As pressões do trade turístico constituem um ingrediente no retorno às atividades econômicas dos destinos turísticos no Brasil em meio a uma pandemia; 2. A governança turística local fomenta medidas de planejamento público sustentável para o desenvolvimento do turismo durante e póspandemia. Hipoteticamente, com base no modus de gerenciamento de crises, ressignificado para este estudo a destinos turísticos no cenário de pandemia (Figura 1), foram construídas as seguintes proposições para cada fase: i) Mitigação, medidas são tomadas visando a redução de efeitos negativos provocados por uma crise; ii) Preparação, medidas são tomadas para se preparar para dar respostas eficazes à crise efetiva; iii) Resposta, medidas são tomadas para lidar com as consequências durante o período da crise efetiva; iv) Recuperação, medidas são planejadas para a retomada do turismo visando ações e reflexões sobre o cenário pós-pandemia.

Figura 1. Representação analítica em destinos turísticos no cenário da pandemia Covid-19

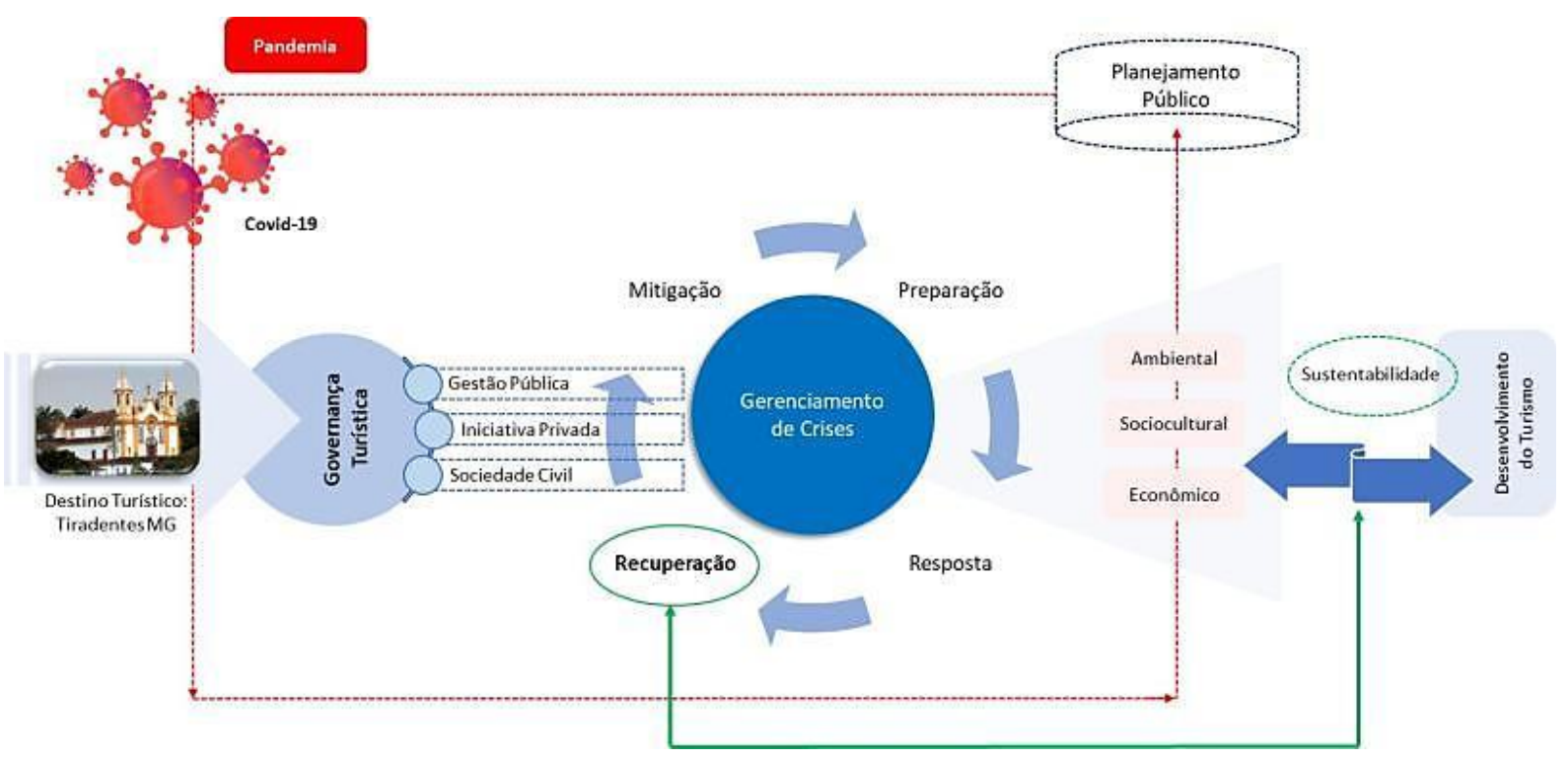

Fonte: Elaboração própria com base nos dados da pesquisa.

Amparado na Lei de Acesso à Informação (Lei Nº 12.527/11), a qual assegura a utilização e divulgação de dados provenientes de perfis abertos e institucionais na internet como fonte de pesquisa pública (Brasil, Presidência da República, 2011), para a análise documental, este estudo aborda o termo documento conforme apregoado por Sá-Silva et al., (2009) e Yamaoka (2009), como todo material de expressiva extensão digital, utilizado para a coleta e análise de dados como mídias e redes sociais, Facebook, Twitter, Youtube, WhatsApp, Blogs, Revistas e Jornais Eletrônicos. Documentos públicos como Boletins Epidemiológicos (11), 
Decretos municipais (25), Planos estaduais (3) e reações populares (102) do perfil público da Prefeitura Municipal de Tiradentes, através do Facebook, foram utilizados neste estudo.

O horizonte temporal para a execução desta pesquisa corresponde aos meses de março a dezembro de 2020. Excepcionalmente, para verificação da propagação da Covid-19 no município em estudo, também analisou-se os dados do Boletim Epidemiológico local até o dia 14 de janeiro de 2021 em decorrência da 'virada de ano' (2020-2021), tendo em vista o período de 14 dias de 'quarentena' estipulado pelos órgãos de saúde (OPAS, 2020; WHO, 2020). Para obter maior precisão e aproximação diante da realidade de disseminação da Covid-19 e das medidas de enfrentamento da crise epidemiológica, foram realizadas entrevistas em profundidade com roteiro semiestruturado, com representantes dos principais segmentos públicos, privados e da comunidade civil de Tiradentes, entre os meses de julho e agosto de 2020. Portanto, tendo em vista o cenário de pandemia, as entrevistas foram realizadas remotamente, por telefone e WhatsApp.

Como o processo de identificação e definição dos participantes da pesquisa requereu certo grau de discernimento, este estudo se justifica como uma amostra não probabilística intencional (Pardal \& Correia, 1995). Portanto, foram selecionados, convidados e entrevistados 10 atores sociais, constituídos pela gestão pública e os stakeholders (atores não públicos: setor privado e sociedade civil) locais (Tabela 2).

Tabela 2. Participantes da pesquisa

\begin{tabular}{|c|c|c|c|}
\hline $\mathbf{N}^{\circ} \mathbf{P P}$ & Órgão de Atuação (OA) & Representatividade e Ocupação Habitual & $\begin{array}{l}\text { Duração da } \\
\text { Entrevista }\end{array}$ \\
\hline 1 & Poder Executivo Municipal & Ator político + Empresário & $00: 32: 14$ \\
\hline 1 & Secretaria Municipal de Saúde & Servidor Público & $00: 09: 42$ \\
\hline 1 & Comitê Gestor da Covid-19 & Servidor Público & $00: 36: 42$ \\
\hline 1 & Secretaria Municipal de Turismo, Cultura, Esporte e Lazer & Servidor Público & $00: 37: 40$ \\
\hline 1 & Câmara Municipal & Ator político + Empresário & $03: 35: 00$ \\
\hline 1 & Conselho Municipal de Turismo (COMTUR) & Diretoria Executiva do COMTUR + Comerciante & $01: 26: 34$ \\
\hline 1 & Conselho Municipal de Desenvolvimento Urbano (COMDUR) & Diretoria Executiva do COMDUR + Servidor Público & $00: 56: 56$ \\
\hline 1 & Associação dos Empresários de Tiradentes (ASSET) & Comerciante & $00: 36: 38$ \\
\hline 1 & Associação dos Moradores Alto da Torre (AMAT) & Diretoria Executiva da AMAT & $00: 34: 49$ \\
\hline 1 & Secretaria Municipal de Finanças & Servidor Público & $00: 25: 29$ \\
\hline \multicolumn{2}{|r|}{ Total: 10 Participantes da Pesquisa (PP) } & $\begin{array}{l}\text { Governança: Gestão Pública (8) - Iniciativa } \\
\text { Privada (4) - Comunidade Civil (1) }\end{array}$ & $\begin{array}{l}\text { Tempo Médio: } \\
55 \text { minutos }\end{array}$ \\
\hline
\end{tabular}

Como é possível verificar na Tabela 2, existem atores que exercem o papel na gestão pública do município ao mesmo tempo em que se configuram como empresários e/ou comerciantes. Assim, acredita-se que a partir desta amostra possam ser observadas as perspectivas dos participantes da pesquisa, inclusive as conflitantes em termos de representatividade e ocupação habitual.

Os Participantes da Pesquisa foram nomeados com a sigla PP, obedecendo os critérios previstos pelo Comitê de Ética, estando de acordo com a Norma Operacional CNS nº 01/2013, item 3.3, "i". A numeração que segue a sigla dos PP (exemplo: PP1 - PP2 etc.) foi realizada no Excel, pelo Visual Basic, através de comando para gerar os números aleatórios, sem repetição. Todas as entrevistas foram gravadas e transcritas na íntegra.

Para as transcrições, utilizou-se o software Voicemeeter 1.0, com auxílio da página https://dictation.io/speech, onde os textos se originaram. Isto posto, foi utilizada a Análise Temática de Conteúdo (cf. Bardin, 2014) a fim de compreender e interpretar os dados 
obtidos, possibilitando identificar as relações entre os atores sociais e a literatura apurada, bem como aproximando-se da realidade sociocultural percebida pelos responsáveis e dependentes do turismo no município de Tiradentes. Outrossim, através da Análise de Conteúdo, foi possível estudar e analisar contrastes e similitudes dos dados coletados, por meio do software IRaMuTeQ 0.7, diante do corpus geral das entrevistas.

\subsection{Unidade de Análise: Tiradentes (MG), Brasil}

O município de Tiradentes está localizado na região do Campo das Vertentes, ao sudeste do estado de Minas Gerais. Sua posição geográfica encontra-se na Região Turística Trilha dos Inconfidentes, composta por mais 22 municípios (Brasil, MTur, 2020).

Figura 2. Localização geográfica de Tiradentes

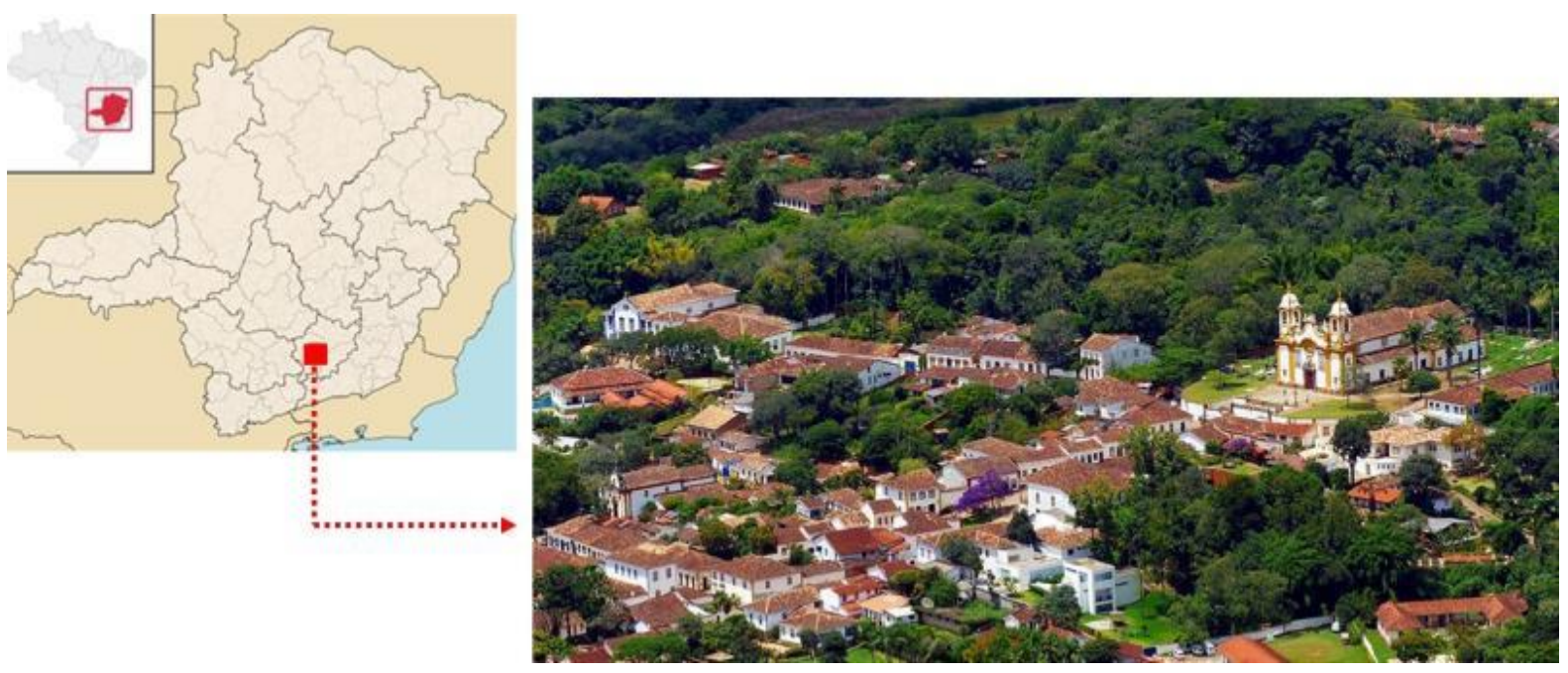

Fonte: Elaboração própria a partir de imagens da internet.

Tiradentes possui a dinamização do seu trade turístico exclusivamente dirigida ao cenário paisagístico, cultural, arquitetônico, natural e religioso. Ressalta-se, sobretudo, os eventos promovidos no município, de proporções nacionais e internacionais. O conjunto arquitetônico e urbanístico de Tiradentes foi tombado em 1938 pelo Instituto do Patrimônio Histórico e Artístico Nacional (IPHAN), e se mantém quase intacto, desde o século XVIII (IPHAN, 2020).

O Instituto Brasileiro de Geografia e Estatística (IBGE) aponta que Tiradentes possui uma população estimada em 8.072 habitantes e o PIB do município é de $\mathrm{R} \$ 162.717 .460,00$ (IBGE, 2018, 2020). Vale destacar que o calendário de eventos local dispõe de uma agenda com 64 tipos de movimentações turísticas anuais, e em períodos de elevado fluxo de circulação de turistas, o município costuma receber aproximadamente 40 mil pessoas (Mediotte, 2020).

\section{Resultados}

O século XXI tem mostrado a todas as lideranças governamentais do mundo que as crises epidemiológicas não devem ser tratadas como uma questão de ‘se', mas ‘quando' elas irão 
surgir (Werneck \& Carvalho, 2020). Conforme demonstrado na Tabela 3, a humanidade já testemunhou pelo menos 7 crises sanitárias causadas por vírus nos últimos 20 anos, o que poderia, grosso modo, suceder uma média de 1 pandemia/epidemia a cada 3 anos.

Tabela 3. Pandemias/epidemias no século XXI

\begin{tabular}{|c|c|c|c|c|c|}
\hline Doença & Tipo & Virus & Continentes Afetados & Paises/Regiōes Mais Afetados & Maior Impacto \\
\hline SARS & Epidemia & SARS-CoV (Coronavírus) & $\begin{array}{l}\text { Asia, Europa, Africa e América (do } \\
\text { Norte) }\end{array}$ & $\begin{array}{l}\text { China, Cingapura, Hong Kong, } \\
\text { Tallândia, Talwan, Vletnă e Canadá }\end{array}$ & 2002 \\
\hline GRIPE AVIÁRIA & Epidemia & $\mathrm{H}_{5} \mathrm{~N}_{1}$ & $\begin{array}{c}\text { Ásia, Europa, África e América (do } \\
\text { Norte) }\end{array}$ & $\begin{array}{l}\text { Coréla do Sul, China, Tallândla, } \\
\text { Vietnã, Japão, Camboja, Laos, } \\
\text { Indonésia e Malásia }\end{array}$ & 2003 \\
\hline GRIPE SUINA & Pandemia & $\mathrm{H}_{1} \mathrm{~N}_{1}$ & $\begin{array}{l}\text { América (do Norte, Central, do Sul), } \\
\text { Europa e Oceania }\end{array}$ & $\begin{array}{c}\text { Estados Unidos, México, Canadá, } \\
\text { Chile, Austrália }\end{array}$ & 2009 \\
\hline EBOLA & Epidemia & Ebolavírus & África & Guiné, Libéria, Serra Leoa e Nigéria & 2014 \\
\hline ZIKA & Epidemia & Zlika Vírus & América do Sul, África e Oceania & $\begin{array}{c}\text { Brasil, Colômbia, El Salvador e Cabo } \\
\text { Verde }\end{array}$ & 2015 \\
\hline MERS & Epidemia & SARS-CoV (Coronavírus) & $\begin{array}{l}\text { Ásia, Europa, África e América (do } \\
\text { Norte) }\end{array}$ & $\begin{array}{l}\text { Arábia Saudita, Emirados Árabes } \\
\text { Unidos, Qatar, Omå, Jordânia, } \\
\text { Kuwait e lêmen }\end{array}$ & 2015 \\
\hline COVID-19 & Pandemla & $\begin{array}{l}\text { SARS-CoV-2 (novo } \\
\text { Coronavirus) }\end{array}$ & $\begin{array}{l}\text { Ásia, Europa, América (do Norte, } \\
\text { Central, do Sul), África e Oceania }\end{array}$ & $\begin{array}{c}\text { Estados Unidos, India, Brasil, Rússia, } \\
\text { Reino Unido, França, Espanha, } \\
\text { Itália... }\end{array}$ & 2020 \\
\hline
\end{tabular}

Fonte: Elaboração própria com base em Croda et al. (2020), Johns Hopkins University (2020), Werneck e Carvalho (2020) e Wilder-Smith (2006).

Deveria ser habitual que os agentes de destinos turísticos refletissem sobre as racionalidades ou intencionalidades de suas ações relativas ao desenvolvimento local sustentável, haja vista que o turismo, além de dinâmico, também comporta-se de maneira sazonal. Como uma de suas características é a indução pela mobilidade de turistas ao redor do mundo, este setor tende a ser o mais afetado em virtude de crises epidemiológicas. A compressão de tempo e espaço diminui as distâncias e facilita o fluxo turístico, todavia em contextos de recessão global como o da pandemia da Covid-19, esses recursos se convertem em vias oportunas para a disseminação de doenças contagiosas.

Entre os desafios para os destinos turísticos em cenários de crises epidemiológicas, aponta-se a retomada do desenvolvimento local, bem como a garantia e o bem-estar da população (residentes e turistas). A propagação vertiginosa de epidemias e pandemias mundo afora têm exposto a todos os líderes governamentais multinível (local, regional, nacional e internacional), principalmente de destinos turísticos, que gerenciar adequadamente uma crise só se faz com planejamento sustentável e governança. Assim, propõe-se na sequência, a re(adaptação) do modus de gerenciamento de crises para destinos turísticos. 
Figura 3. Modus de gerenciamento de crises para destinos turísticos

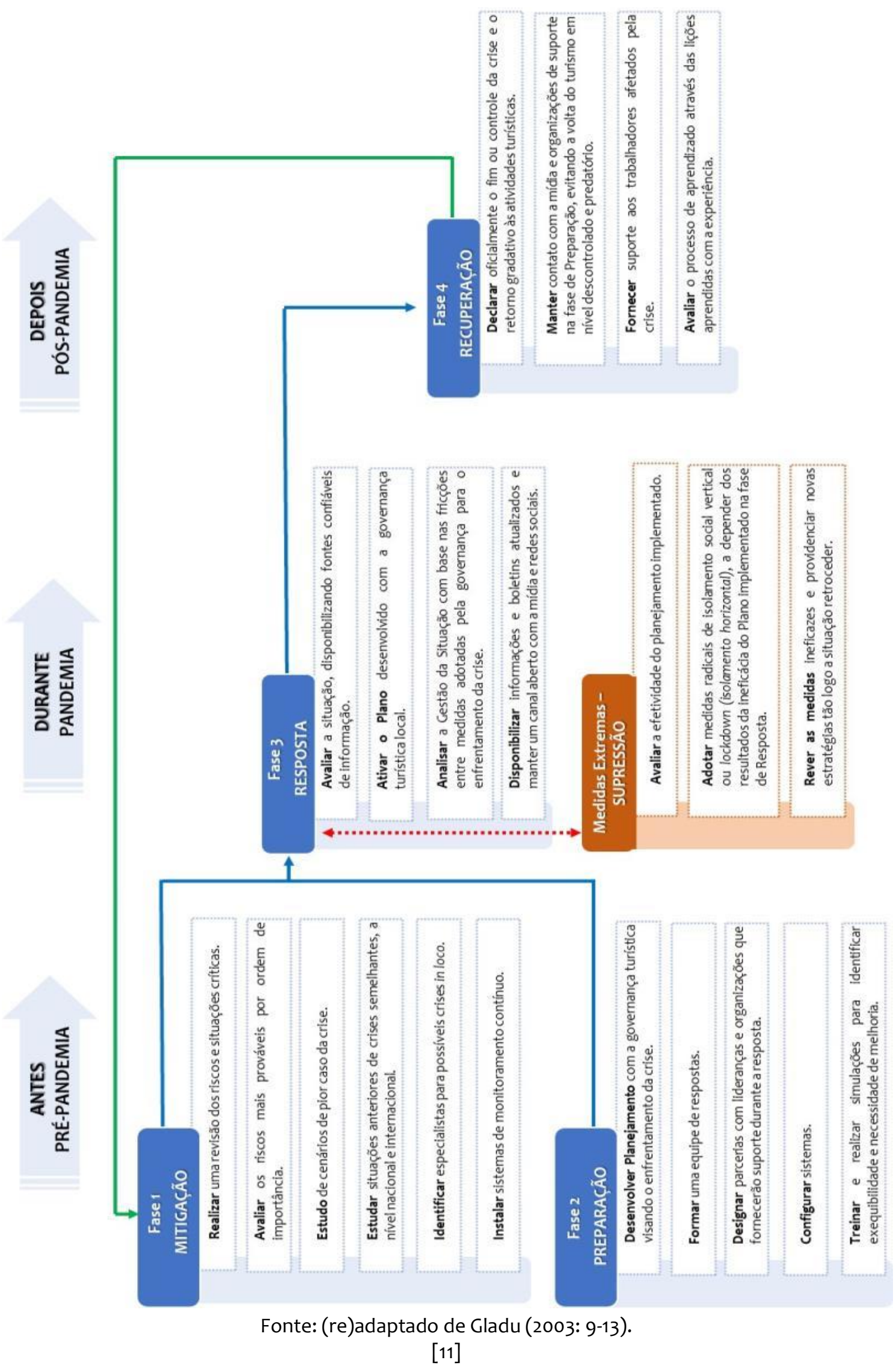


Em decorrência dos resultados apresentados nesta pesquisa, verificou-se que no município de Tiradentes as Fases 1 (Mitigação) e 2 (Preparação) não foram realizadas ou não identificadas, no âmbito da Pré-pandemia. Portanto, este estudo se condensou às Fases 3 (Resposta) e 4 (Recuperação), haja vista que todo o contexto empírico do modus de gerenciamento de crises fora identificado nestas duas últimas fases.

É nesse contexto de inseguranças e instabilidade econômica que, expressivamente observado nas entrevistas, a preocupação da flexibilização e reabertura do trade tem sido pauta de disparidades entre os empresários, trabalhadores, sociedade civil e autoridades sanitárias.

Apresenta-se, na Tabela 4, a relação de todos os decretos disponibilizados pelo site institucional da Prefeitura Municipal de Tiradentes quanto às ações referentes à Covid-19, no ano de 2020, os quais auxiliaram a execução desta seção.

Tabela 4. Decretos Municipais Covid-19 - Tiradentes 2020

\begin{tabular}{|c|c|c|}
\hline Mês & Data & Decreto Municipal (DM) \\
\hline \multirow{4}{*}{ 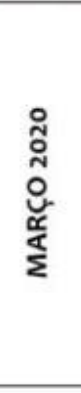 } & 16.03 .2020 & $\begin{array}{l}\text { DM 3.105 - Declara situação de emergência em saúde pública no município de Tiradentes, em } \\
\text { razão do surto de doença respiratória - novo Coronavírus. }\end{array}$ \\
\hline & 17.03 .2020 & $\begin{array}{l}\text { DM 3.106 - Suspensão das aulas da Rede Municipal por } 6 \text { dias ( } 19 \text { a } 24 \text { de março); suspensão } \\
\text { de eventos a partir de } 200 \text { pessoas por } 15 \text { dias e dá outras providências. }\end{array}$ \\
\hline & 19.03 .2020 & $\begin{array}{l}\text { DM 3.108 - Institui o Comitê Gestor Extraordinário Covid-19, composto por } 9 \text { autoridades } \\
\text { locais; suspensão por tempo indeterminado das atividades e serviços que impliquem } \\
\text { aglomeração de pessoas e dá outras providências. Este decreto revoga o DM } 3.106 \text { e terá } \\
\text { validade de } 10 \text { dias a partir de } 23.03 .20 \text {. }\end{array}$ \\
\hline & 26.03 .2020 & $\begin{array}{l}\text { DM 3.112 - Abre crédito suplementar no valor de R\$22.787,42 para cobertura de custo da Covid- } \\
\text { 19, com inclusão de fonte e dá outras providências. }\end{array}$ \\
\hline Mês & Data & Decreto Municipal (DM) \\
\hline \multirow{6}{*}{ 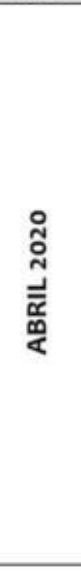 } & 06.04 .2020 & $\begin{array}{l}\text { DM } 3.117 \text { - Dispõe sobre alteração do DM } 3.108 \text { autorizando o funcionamento de serviços } \\
\text { essenciais. }\end{array}$ \\
\hline & 06.04 .2020 & $\begin{array}{l}\text { DM 3.119 - Dispõe sobre medidas trabalhistas para os servidores públicos municipais relativas a } \\
\text { férias, feriados, teletrabalho, jornada de trabalho e dá outras providências. }\end{array}$ \\
\hline & 06.04 .2020 & $\begin{array}{l}\text { DM } 3.121 \text { - Declara estado de Calamidade Pública no município de Tiradentes para fins de } \\
\text { prevenção e enfrentamento à pandemia decorrente do novo Coronavírus (Covid-19). }\end{array}$ \\
\hline & 13.04 .2020 & $\begin{array}{l}\text { DM 3.124 - Institui o Comitê Gestor Extraordinário Covid-19, composto por } 9 \text { autoridades locais; } \\
\text { suspensão por tempo indeterminado das atividades e serviços que impliquem aglomeração de } \\
\text { pessoas e dá outras providências. Este decreto revoga o DM 3.108 e vigorará até 04.05.2020. }\end{array}$ \\
\hline & 15.04 .2020 & $\begin{array}{l}\text { DM } 3.126 \text { - Dispõe sobre o uso obrigatório de máscaras a partir de } 20.04 .2020 \text { em transportes de } \\
\text { passageiros, para acesso aos estabelecimentos essenciais e para atividades em repartições } \\
\text { públicas. }\end{array}$ \\
\hline & 29.04 .2020 & $\begin{array}{l}\text { DM } 3.135 \text { - Dispõe sobre o uso obrigatório de máscaras para o acesso e desempenho das } \\
\text { atividades, nos prédios públicos, comércio em geral e vias públicas no âmbito do município de } \\
\text { Tiradentes, a partir de } 05.05 .2020 \text { e vigorará enquanto perdurar a pandemia da Covid-19. }\end{array}$ \\
\hline Mês & Data & Decreto Municipal (DM) \\
\hline \multirow{3}{*}{ 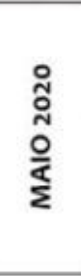 } & 05.05 .2020 & $\begin{array}{l}\text { DM 3.140 - Dispõe sobre regras para horário de funcionamento e atendimento às repartições } \\
\text { públicas do município, revoga artigos e incisos do DM 3.124 que passa a vigorar até 12.05.2020. } \\
\text { Institui o Alvará de Licença Covid-19. }\end{array}$ \\
\hline & 12.05 .2020 & $\begin{array}{l}\text { DM } 3.147 \text { - Dispõe sobre o prazo de vigor do DM 3.124, que prorrogará por tempo } \\
\text { indeterminado. }\end{array}$ \\
\hline & 26.05 .2020 & $\begin{array}{l}\text { DM } 3.159 \text { - Dispõe sobre medidas acerca de casos suspeitos nas barreiras sanitárias do } \\
\text { município de Tiradentes, com vigor enquanto perdurar a pandemia da Covid-19. }\end{array}$ \\
\hline
\end{tabular}




\begin{tabular}{|c|c|c|}
\hline Mês & Data & Decreto Municipal (DM) \\
\hline \multirow{2}{*}{ 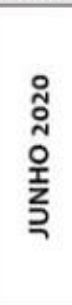 } & 02.06 .2020 & $\begin{array}{l}\text { DM 3.164 - Dispõe sobre a adesão do município de Tiradentes ao Plano Minas Consciente, do } \\
\text { Estado de Minas Gerais, que qualifica o município para a Onda Branca, revoga o DM } 3.124 \text { e dá } \\
\text { outras providências. }\end{array}$ \\
\hline & 05.06 .2020 & $\begin{array}{l}\text { DM 3.167 - Considerando o aumento de casos de Covid-19 e a necessidade de medidas mais } \\
\text { restritivas, revoga o DM } 3.164 \text {, suspendendo todas as atividades não essenciais, com vigor } \\
\text { enquanto perdurar o estado de emergência e calamidade causado pela Covid-19 ou até a } \\
\text { Macro Região Centro-Sul (representada pelo município de São João del Rei - MG) possuir o } \\
\text { mínimo necessário de leitos para adesão ao Plano Minas (onsciente, de MG). }\end{array}$ \\
\hline
\end{tabular}

\begin{tabular}{|c|c|c|}
\hline Mês & Data & Decreto Municipal (DM) \\
\hline \multirow{5}{*}{ 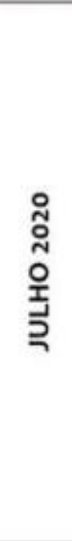 } & 01.07 .2020 & $\begin{array}{l}\text { DM } 3.192 \text { - Dispõe sobre a proibição de entrada de pessoas no município de Tiradentes para } \\
\text { fins turísticos e visitações, visando a contenção do avanço da pandemia do coronavírus e dá } \\
\text { outras providências. }\end{array}$ \\
\hline & 02.07 .2020 & $\begin{array}{l}\text { DM 3.194 - Altera e Revoga o DM 3.192. Mantém a proibição da entrada de pessoas, em } \\
\text { especial de visitantes, no município de Tiradentes salvo por motivo de força maior como } \\
\text { aquisição de gêneros alimentícios, medicamentos, produtos médico hospitalares, produtos } \\
\text { de limpeza e higiene pessoal e dá outras providências. }\end{array}$ \\
\hline & 10.07 .2020 & $\begin{array}{l}\text { DM 3.203 - Dispõe sobre a adesão do município de Tiradentes ao Plano Minas Consciente, com } \\
\text { vigor a partir do dia 13.07.2020 e dá outras providências. }\end{array}$ \\
\hline & 29.07.2020 & $\begin{array}{l}\text { DM 3.224 - Dispõe sobre a progressão de "Onda" [progride para a Onda Amarela] do Plano } \\
\text { Minas Consciente, com vigor a partir de 01.08.2020 e dá outras providências. }\end{array}$ \\
\hline & 29.07.2020 & $\begin{array}{l}\text { DM } 3.229 \text { - Dispõe sobre autorização para o funcionamento de igrejas, templos religiosos e } \\
\text { afins com condições de funcionamento, durante o periodo de enfrentamento da pandemia } \\
\text { da Covid-19. }\end{array}$ \\
\hline
\end{tabular}

Nos meses de AGOSTO, SETEMBRO e OUTUBRO não foram identificados Decretos Municipais disponibilizados pelo site institucional do município de Tiradentes.

\begin{tabular}{|c|c|c|}
\hline Mês & Data & Decreto Municipal (DM) \\
\hline 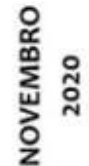 & 27.11 .2020 & $\begin{array}{l}\text { DM 3.318 - Dispõe sobre a regressão da “Onda” [regride para a Onda Amarela] do [novo] Plano } \\
\text { Minas Consciente e dá outras providências. }\end{array}$ \\
\hline
\end{tabular}

\begin{tabular}{|c|c|c|}
\hline Mês & Data & Decreto Municipal (DM) \\
\hline \multirow{3}{*}{ 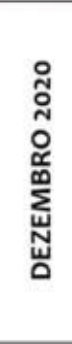 } & 18.12 .2020 & $\begin{array}{l}\text { DM } 3.343 \text { - Dispõe sobre a regressão da “Onda” [regride para a Onda Vermelha] do [novo] } \\
\text { Plano Minas Consciente e dá outras providências. }\end{array}$ \\
\hline & 24.12 .2020 & $\begin{array}{l}\text { DM } 3.347 \text { - Concede, em caráter excepcional para o mês de dezembro de 2020, o } \\
\text { funcionamento de estabelecimentos que exploram atividades de lanchonetes e restaurantes } \\
\text { para consumo no local, com restrições de horários. }\end{array}$ \\
\hline & 31.12 .2020 & $\begin{array}{l}\text { DM 3.357 - Dispõe sobre a manutenção da "Onda Vermelha" no município, tendo em vista, } \\
\text { inclusive, o teor da Ação Civil Pública ajuizada pelo Ministério Público de MG, deferido } \\
\text { judicialmente na Comarca de São João del Rei, em 30.12.2020. Revoga disposições dessa } \\
\text { natureza, contidas no DM 3.347. }\end{array}$ \\
\hline
\end{tabular}

Fonte: Elaboração própria com base em Tiradentes, Prefeitura Municipal (2020a).

\subsection{Fase de resposta (3): Medidas são tomadas para lidar com as consequências durante 0 período da crise efetiva}

Nessa fase, as ações prescritas no planejamento são efetivamente implementadas a fim de que a disseminação da crise epidemiológica possa ser conduzida pela governança local de forma responsável e segura. Sendo assim, "as atividades de resposta são propostas para 
assumir o controle e conter impactos negativos. Deve-se entender que as atividades de resposta são interativas ou simultâneas devido à incerteza em torno de crises ou emergências" (Gladu, 2003: 12).

Werneck e Carvalho (2020: 1) assinalam que o objetivo é conter a disseminação da doença "para os grupos com maior risco de apresentarem quadros clínicos graves, além, claro, do isolamento dos casos positivos identificados", sobretudo das medidas para o 'achatamento' da curva de contaminações. Os autores preconizam que o distanciamento social ou 'isolamento vertical' inicia-se a partir das atividades que envolvem maior aglomeração de pessoas, como os eventos (primeiro de grande porte, depois os eventos menores), as atividades escolares entre outras, que envolvem aglomerações.

Figura 4. Fase de resposta - Tiradentes

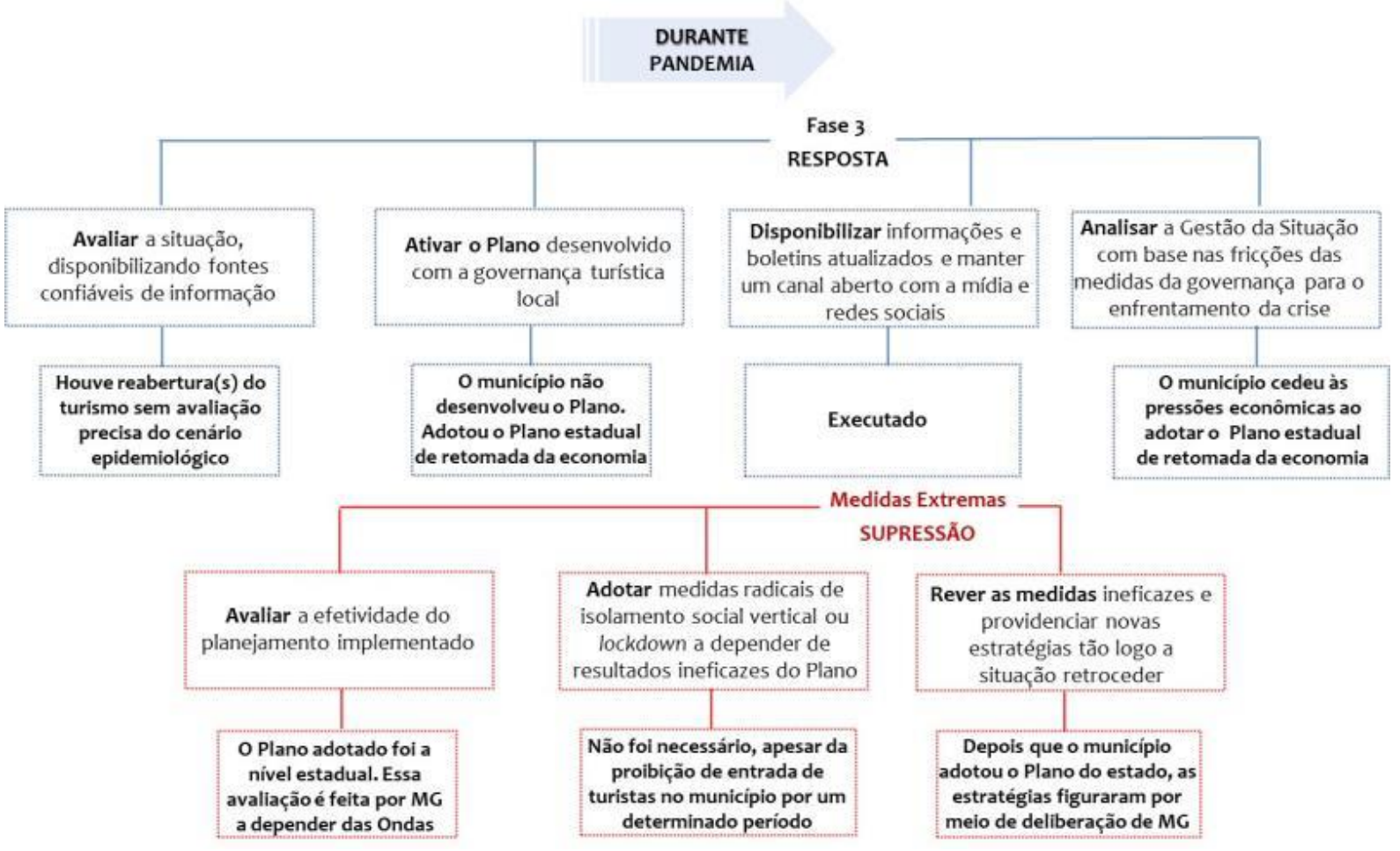

Fonte: Elaboração própria.

A situação da Covid-19 em Tiradentes, diante dos dados coletados, foi determinada pela reação do trade turístico. Desde o dia 16.03.20, quando o município, por meio do DM 3.105 decretou situação de emergência em saúde pública, em virtude da pandemia declarada pela OMS em 11.03.2020, até o momento em que decidiu adotar o plano estadual Minas Consciente (Minas Gerais, 2020), não havia constatado nenhum caso da Covid-19.

Observou-se, também, que instituições públicas e privadas firmaram Parcerias com o Poder Executivo do município no intuito de oferecerem um Treinamento para os empresários e comerciantes adotarem medidas sanitárias, visando a reabertura das atividades econômicas e a redução dos impactos causados com o fechamento do trade. Essa ação dividiu opiniões, ainda mais por não ter havido uma fase de testes para identificar fragilidades e oportunidades de melhoria. 
No primeiro dia de treinamento nós ouvimos falar sobre produtores rurais. Comprar do local, comprar do cara que está próximo. Esquecer compra de Rio e São Paulo. Comprar aqui pra diminuir o contato com esses níveis externos, com o nível de contaminação e buscar valorizar a economia local. No segundo dia, o treinamento era específico para bares e restaurantes. No terceiro dia, a mulher falou sobre o protocolo. Cara, eu tive vontade de chorar. Falei assim: "Ninguém vai conseguir abrir, a adequação é absurda! Eu, sinceramente, estou com muito medo". No quarto dia, a gente falou sobre finanças. Aí eu falei assim: "Não, agora eu tenho certeza de que ninguém vai abrir" (PP9).

Após a instituição dos DM (3.105, 3.106, 3.108), o município passou a enfrentar um impasse social e econômico. De um lado, os apoiadores pelas medidas de suspensão das atividades turísticas, notadamente implicadas ao trade. De outro lado, os grupos de pressão para a flexibilização econômica. Ainda, tampouco se percebeu a inclusão da sociedade civil nas deliberações sobre as ações para a reabertura do turismo no município.

Não estamos sendo chamados para participar de nada. É muito fácil um empresário botar a gente pra trabalhar, enquanto ele fica em casa protegido do vírus e ganhando dinheiro. Enquanto nós, trabalhadores, ficamos expostos. Aqui é uma cidade pequena e as pessoas são muito humildes. Não tenho certeza se todo mundo vai entender como usar corretamente um EPI [Equipamento de Proteção Individual], porque estamos acostumados a atender as pessoas calorosamente. (...) Então, nosso medo é não termos tempo de nos adaptar com isso [sobre a reabertura do turismo], como querem os empresários e a prefeitura. Sem contar que, se as pessoas começarem a falecer por causa do vírus, não temos cemitério para sepultar muita gente (PP6).

Tais argumentos reforçam a noção de Core Governance (Mediotte, 2020: 19), a qual se refere a "uma governança centrada em um núcleo de atores, os quais determinam o desenvolvimento do turismo no destino turístico" como uma forma de legitimar seus interesses. Portanto, o cenário de pandemia revela que a sociedade civil tem sido periférica nas tomadas de decisões.

Em um encontro realizado entre o Poder Executivo Municipal, o Comitê Gestor Covid-19, empresários e comerciantes locais, no dia 01.06.2020, fica explícita a pressão econômica para a retomada das atividades econômicas, suspensas até então. Traços dessa perspectiva não são concebidos de acordo com os preceitos de planejamento sustentável (Irving et al., 2020; Mediotte, 2020; Paraskevas et al., 2013), mas sim como um atributo de crescimento econômico a curto prazo, sobretudo atrelado à própria concepção de desenvolvimento turístico pelos atores sociais do município, representados pela gestão pública e stakeholders.

(Empresário Local): A cidade não tem casos confirmados e a Santa Casa [município de São João del Rei] está com os leitos vazios. O desemprego vai aumentar, precisamos abrir. A prefeitura cobrou o alvará e a capacitação e os empresários fizeram a sua parte, houve grande adesão. (...) Enquanto os empresários estão cumprindo todas as exigências dos órgãos competentes, o serviço de hospedagem informal, funciona normalmente (Tiradentes, 2020c). 
(Poder Executivo Municipal): Durante todo esse tempo de pandemia, Tiradentes é um dos municípios que mais cumpre as normas para resguardar a saúde da população, inclusive, agradeço a todos pela compreensão. Chegou a hora de abraçar o Minas Consciente para devolver a autonomia econômica e emocional dos empreendedores e de pais de famílias, tutores e de todo o povo tiradentino, respeitando as normas de distanciamento e demais medidas previstas no Alvará Covid-19 (Tiradentes, Prefeitura Municipal, 2020c).

Um dia depois da reunião, deu-se início à proliferação descontrolada da Covid-19 no município, por meio da promulgação do DM 3.164, revogando o DM 3.124 (que suspendera por tempo indeterminado as atividades e serviços que implicavam aglomeração de pessoas), fazendo adesão ao Plano Minas Consciente. Esse plano possui 3 pilares (Tabela 5):

Tabela 5. Minas Consciente

\begin{tabular}{|c|l|}
\hline \multicolumn{2}{|c|}{ Plano Minas Consciente - Minas Gerais } \\
\hline PILAR 1 & Retomada da atividade econômica em ondas, de forma gradual e segura. \\
\hline PILAR 2 & $\begin{array}{l}\text { Tomada de decisão a partir de indicadores que avaliem a capacidade assistencial e a incidência } \\
\text { da doença. }\end{array}$ \\
\hline PILAR 3 & $\begin{array}{l}\text { Definição de critérios de funcionamento e protocolos sanitários para o poder público, } \\
\text { empresas, trabalhadores e cidadãos de forma a garantir o distanciamento social e os cuidados } \\
\text { necessários para evitar a transmissão da doença. }\end{array}$ \\
\hline
\end{tabular}

Fonte: Elaboração própria com base em Minas Gerais (2020: 9).

A adesão do município ao Plano do estado de $M G$ fomentou a flexibilização das atividades econômicas de acordo com as chamadas "Ondas" (Tabela 6). Segundo o Plano Minas Consciente, as "Ondas" referem-se aos tipos de serviços e atividades econômicas, às quais concedem aos municípios aderentes ao Plano a abertura ou o fechamento, de acordo com índices de contágio e propagação da Covid-19. Além disso, "a cada 21 dias, ou intervalo inferior a depender dos dados monitorados, haverá uma avaliação dos dados da região se devemos avançar, manter ou retroceder [as Ondas]" (Minas Gerais, 2020: 40).

O Plano Minas Consciente foi atualizado diversas vezes durante o ano de 2020. Para melhor ilustrar os serviços e atividades econômicas vinculados em cada "Onda", apresentase, na Tabela 7, a síntese da evolução das versões de 2020, destacando-se apenas os Planos relativos aos DM disponibilizados no site institucional da Prefeitura de Tiradentes. 
Tabela 6. As “Ondas” do Plano Minas Consciente e suas incidências no turismo em Tiradentes

\begin{tabular}{|c|c|c|c|c|}
\hline ONDAS & VERSÃO 1.0 (ABR-MAI 2020) & VERSÃO 2.0 (MAI-JUL 2020) & $\begin{array}{l}\text { INVERSÃO } \\
\text { ONDAS }\end{array}$ & $\begin{array}{l}\text { VERSÃO } 3.2 \text { (SET-DEZ 2020) } \\
\text { Inversão das Ondas }\end{array}$ \\
\hline & $\begin{array}{c}\text { Funcionamento das atividades } \\
\text { essenciais. }\end{array}$ & $\begin{array}{l}\text { Funcionamento das atividades } \\
\text { essenciais. }\end{array}$ & & $\begin{array}{l}\text { Funcionamento das atividades } \\
\text { essenciais. }\end{array}$ \\
\hline & $\begin{array}{l}\text { Incidência no Turismo: Alto } \\
\text { impacto. }\end{array}$ & $\begin{array}{l}\text { Incidência no Turismo: Médio } \\
\text { impacto. }\end{array}$ & & $\begin{array}{l}\text { Incidência no Turismo: Médio } \\
\text { impacto. }\end{array}$ \\
\hline $\begin{array}{l}\text { ONDA } \\
\text { VERDE }\end{array}$ & $\begin{array}{l}\text { Barreiras restritivas de } \\
\text { entrada e circulação de } \\
\text { turistas, fechamento do trade } \\
\text { e de toda cadeia turistica. }\end{array}$ & $\begin{array}{l}\text { Barreiras flexiveis de entrada e } \\
\text { circulação de turistas, } \\
\text { fechamento do trade e de } \\
\text { outros serviços vinculados ao } \\
\text { turismo, embora admita-se o } \\
\text { funcionamento de Hotéis e } \\
\text { outras acomodações. }\end{array}$ & $\begin{array}{c}\text { ONDA } \\
\text { VERMELHA }\end{array}$ & $\begin{array}{l}\text { Barreiras flexíveis de entrada e } \\
\text { circulação de turistas, fechamento } \\
\text { do trode e de outros serviços } \\
\text { vinculados ao turismo, embora } \\
\text { admita-se o funcionamento de } \\
\text { Hotéis e afins. }\end{array}$ \\
\hline & $\begin{array}{l}\text { Liberação de atividades } \\
\text { econômicas de baixo risco. } \\
\text { Incidência no Turismo: Médio } \\
\text { Impacto. }\end{array}$ & $\begin{array}{l}\text { Liberação de atividades } \\
\text { econômicas de baixo risco. } \\
\text { Incidência no Turismo: Médio } \\
\text { Impacto. }\end{array}$ & & \\
\hline $\begin{array}{l}\text { ONDA } \\
\text { BRANCA }\end{array}$ & $\begin{array}{l}\text { Barreiras flexíveis de entrada e } \\
\text { circulação de turistas, sem } \\
\text { hospedagens, fechamento do } \\
\text { trade e flexibilização de } \\
\text { atividades de souvenirs e afins. }\end{array}$ & $\begin{array}{l}\text { Barreiras flexíveis de entrada e } \\
\text { circulação de turistas, } \\
\text { admitindo-se hospedagens, } \\
\text { fechamento do trade e } \\
\text { flexibilização de atividades de } \\
\text { souvenirs e afins. }\end{array}$ & $\begin{array}{l}\text { ONDA } \\
\text { BRANCA }\end{array}$ & Extinguida. \\
\hline \multirow{4}{*}{$\begin{array}{l}\text { ONDA } \\
\text { AMARELA }\end{array}$} & $\begin{array}{l}\text { Liberação de atividades } \\
\text { econômicas de médio risco. }\end{array}$ & $\begin{array}{l}\text { Liberação de atividades } \\
\text { econômicas de médio risco. }\end{array}$ & & $\begin{array}{l}\text { Liberação das atividades de risco } \\
\text { intermediário. }\end{array}$ \\
\hline & $\begin{array}{l}\text { Incidência no Turismo: Médio } \\
\text { Impacto. }\end{array}$ & $\begin{array}{l}\text { Incidência no Turismo: Médio } \\
\text { Impacto. }\end{array}$ & & $\begin{array}{l}\text { Incidência no Turismo: Baixo } \\
\text { impacto. }\end{array}$ \\
\hline & $\begin{array}{l}\text { Barreiras flexíveis de entrada e } \\
\text { circulação de turistas, sem }\end{array}$ & $\begin{array}{l}\text { Barreiras flexíveis de entrada e } \\
\text { circulação de turistas, }\end{array}$ & & $\begin{array}{l}\text { Barreiras flexiveis de entrada e } \\
\text { circulação de turistas, }\end{array}$ \\
\hline & $\begin{array}{c}\text { hospedagens, fechamento do } \\
\text { trade e flexibilização de } \\
\text { atividades de souvenirs, lojas } \\
\text { de departamento, vestuários e } \\
\text { afins. }\end{array}$ & $\begin{array}{l}\text { admitindo-se hospedagens, } \\
\text { fechamento do trade e } \\
\text { flexibilização de atividades de } \\
\text { souvenirs, lojas de } \\
\text { departamento, vestuários e } \\
\text { afins. }\end{array}$ & AMARELA & $\begin{array}{l}\text { flexibilização do trade e de outros } \\
\text { serviços vinculados ao turismo, } \\
\text { admitindo-se o funcionamento de } \\
\text { hotéis e afins, atividades culturais } \\
\text { com protocolos restritivos e de } \\
\text { ensino. }\end{array}$ \\
\hline \multirow[b]{3}{*}{$\begin{array}{c}\text { ONDA } \\
\text { VERMELHA }\end{array}$} & $\begin{array}{l}\text { Liberação de atividades } \\
\text { económicas de alto risco. }\end{array}$ & $\begin{array}{l}\text { Liberação de atividades } \\
\text { econômicas de alto risco. }\end{array}$ & & $\begin{array}{l}\text { Liberação das atividades } \\
\text { econômicas de alto risco. }\end{array}$ \\
\hline & $\begin{array}{l}\text { Incidência no Turismo: Baixo } \\
\text { Impacto. }\end{array}$ & $\begin{array}{l}\text { Incidência no Turismo: Baixo } \\
\text { Impacto. }\end{array}$ & & $\begin{array}{l}\text { Incidência no Turismo: Impacto } \\
\text { Nulo. }\end{array}$ \\
\hline & $\begin{array}{l}\text { Barreiras flexíveis de entrada e } \\
\text { circulação de turistas, } \\
\text { admitindo-se as hospedagens, } \\
\text { fechamento do trade e } \\
\text { flexibilização de atividades de } \\
\text { souvenirs, lojas de } \\
\text { departamento e decoração, } \\
\text { vestuários, salöes de beleza, } \\
\text { academias e afins. }\end{array}$ & $\begin{array}{l}\text { Barreiras flexíveis de entrada e } \\
\text { circulação de turistas, } \\
\text { admitindo-se as hospedagens, } \\
\text { fechamento do trade e } \\
\text { flexibilização de atividades de } \\
\text { souvenirs, lojas de } \\
\text { departamento e decoração, } \\
\text { vestuários, salões de beleza, } \\
\text { academias e afins. }\end{array}$ & $\begin{array}{l}\text { ONDA } \\
\text { VERDE }\end{array}$ & $\begin{array}{c}\text { Extinção das Barreiras sanitárias, } \\
\text { abertura do trode e de todos os } \\
\text { serviços e atividades vinculados } \\
\text { ao turismo, com protocolo padrão } \\
\text { e de ensino. }\end{array}$ \\
\hline
\end{tabular}

Fonte: Elaboração própria com base nos Planos estaduais Minas Consciente (Minas Gerais, 2020). 
Tabela 7. Serviços e atividades das “Ondas” do Plano Minas Consciente

\begin{tabular}{|c|c|c|c|c|}
\hline ONDAS & VERSÃO 1.o (ABR-MAI 2020) & VERSÃO 2.0 (MAI-JUL 2020) & $\begin{array}{l}\text { INVERSÃO } \\
\text { ONDAS }\end{array}$ & $\begin{array}{c}\text { VERSÃO } 3.2 \text { (SET-DEZ 2020) } \\
\text { Inversão das Ondas }\end{array}$ \\
\hline $\begin{array}{l}\text { ONDA } \\
\text { VERDE }\end{array}$ & $\begin{array}{l}\text { Agropecuária - Alimentos - } \\
\text { Bancos e Seguros - Cadeia } \\
\text { Produtiva e atividades } \\
\text { acessórias essenciais - } \\
\text { Construção civil e afins - } \\
\text { Indústria em geral - Saúde - } \\
\text { Telecomunicação, } \\
\text { comunicação e imprensa - } \\
\text { Transporte público, veículos } \\
\text { e correios - Tratamento } \\
\text { água, esgoto e resíduos. }\end{array}$ & $\begin{array}{l}\text { Agropecuária - Alimentos - } \\
\text { Bancos e Seguros - Cadeia } \\
\text { Produtiva e atividades acessórias } \\
\text { essenciais - Construção civile afins } \\
\text { - Fábrica, energia, extração, } \\
\text { produção, siderúrgica e afins - } \\
\text { Saúde - Telecomunicação, } \\
\text { comunicação e imprensa - } \\
\text { Transporte público, veiculos e } \\
\text { correios - Tratamento água, } \\
\text { esgoto residuos- Hotéis eutras } \\
\text { acomodações que estejam } \\
\text { direcionadas exclusivamente para } \\
\text { auxiliar a manutenção de } \\
\text { atividades essenciais. }\end{array}$ & $\begin{array}{l}\text { ONDA } \\
\text { VERMELHA }\end{array}$ & $\begin{array}{l}\text { Agropecuária - Alimentos - Bancos } \\
\text { e seguro - Cadeia produtiva e } \\
\text { atividades assessórias essenciais - } \\
\text { Construção civil e afins - Fábrica, } \\
\text { energia, extração, produção, } \\
\text { siderúrgica e afins - Saúde - } \\
\text { Telecomunicação, comunicação e } \\
\text { imprensa - Transporte, veículos e } \\
\text { correios. Tratamento água, } \\
\text { esgoto e residuos - Hotéis e afins - } \\
\text { Aulas práticas de cursos de saúde } \\
\text { que tenham atendimento à } \\
\text { população. }\end{array}$ \\
\hline $\begin{array}{l}\text { ONDA } \\
\text { BRANCA }\end{array}$ & $\begin{array}{l}\text { Antiguidades e objetos de } \\
\text { arte - Armas e fogos de } \\
\text { artificio-Artigos esportivos } \\
\text { e jogos eletrónicos - } \\
\text { Floriculturas - Móveis, } \\
\text { tecidos e afins - Outras } \\
\text { atividades acessórias. }\end{array}$ & $\begin{array}{l}\text { Antiguidades e objetos de arte - } \\
\text { Armas e fogos de artificio-Artigos } \\
\text { esportivos e jogos eletrônicos - } \\
\text { Floriculturas - Móveis, tecidos e } \\
\text { afins - Outras atividades } \\
\text { acessónias. }\end{array}$ & $\begin{array}{l}\text { ONDA } \\
\text { BRANCA }\end{array}$ & Extinguida. \\
\hline $\begin{array}{l}\text { ONDA } \\
\text { AMARELA }\end{array}$ & $\begin{array}{l}\text { Departamento e Variedades } \\
\text { - Livros, papelaria, discos e } \\
\text { revistas - Vestuário. }\end{array}$ & $\begin{array}{l}\text { Departamento e Variedades - } \\
\text { Livros, papelaria, discos e revistas } \\
\text { - Vestuário. }\end{array}$ & $\begin{array}{l}\text { ONDA } \\
\text { AMARELA }\end{array}$ & $\begin{array}{l}\text { Antiguidades e objetos de arte - } \\
\text { Armas e fogos de artificio-Artigos } \\
\text { esportivos e jogos eletrônicos - } \\
\text { Floriculturas - Móveis, tecidos e } \\
\text { afins-Outras atividades acessórias } \\
\text { - Departamento e Variedades - } \\
\text { Livros, papelaria, discos e revistas } \\
\text { - Vestuário- Decoração, Design e } \\
\text { paisagismo- Duty free-Formação } \\
\text { de condutores - Informática e } \\
\text { comunicação não essenciais - Joias } \\
\text { e bijuterias - Salões de beleza e } \\
\text { estética - Clubes, academias, } \\
\text { atividades de lazer e esportivas } \\
\text { (protocolos restritivos) - Atrativos } \\
\text { culturais e naturais (protocolos } \\
\text { restritivos)- Ensino de graduação, } \\
\text { pós-graduação e outras atividades } \\
\text { de ensino. }\end{array}$ \\
\hline $\begin{array}{l}\text { ONDA } \\
\text { VERMEUHA }\end{array}$ & $\begin{array}{l}\text { Decoração, Design e } \\
\text { paisagismo - Duty free - } \\
\text { Formação de condutores - } \\
\text { Hotéis e afins - Informática e } \\
\text { comunicação não essencial - } \\
\text { Joias e Bijuterias - Salōes de } \\
\text { beleza e estética. }\end{array}$ & $\begin{array}{l}\text { Decoração, Design e paisagismo - } \\
\text { Duty free - Formação de } \\
\text { condutores - Hotéis e afins - } \\
\text { Informática e comunicação não } \\
\text { essencial - Joias e Bijuterias - } \\
\text { Salões de beleza e estética. }\end{array}$ & $\begin{array}{l}\text { ONDA } \\
\text { VERDE }\end{array}$ & $\begin{array}{l}\text { Eventos, museus, cinemas e } \\
\text { incentivadores de grandes } \\
\text { aglomerações - Clubes, academias, } \\
\text { atividades de lazer e esportivas } \\
\text { (com protocolo padrão) - Turismo } \\
\text { em geral, incluindo atrativos } \\
\text { culturais e naturais (em onda } \\
\text { verde com protocolos padrão) - A } \\
\text { educação básica. }\end{array}$ \\
\hline
\end{tabular}

Fonte: Elaboração própria com base nos Planos estaduais Minas Consciente (Minas Gerais, 2020).

A partir da flexibilização das barreiras sanitárias e abertura do trade turístico no município de Tiradentes, a população se mostrou insatisfeita com a falta de fiscalização no território municipal, em decorrência do número elevado de pessoas sem o uso das máscaras e das aglomerações. 
Figura 5. Reações populares em Tiradentes - máscaras e fiscalização

Prefeitura de Tiradentes será q não rola uma parceria com o Exército e a PM para retirar das ruas as pessoas sem máscara e as aglomeraçōes? Já são oito meses de apelo, tá ficando muito arriscado e não dá simplesmente pra fechar tudo, pq prejudicaria a fonte de renda do trabalhador.

Curtir-Responder - 8 sen

todo final de semana o Largo das Forras está igual ao um carnaval.

Cadê a fiscalização ??? Cadê o Poder público?

Curtir - Responder - 8 sem
Só na base mesmo do "apelo" pra que cumpram os protolocos! Sejam bem vindos à Disney Mineira

Curtir - Responder - 8 sem

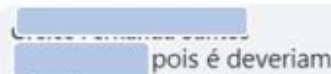

falar isso no final de semana quando a cidade está Hiper

lotada de poderosos

aglomerados tomando shop show ao vivo nos restaurantes e bares, nós Tiradentinos que levamos ferro pq eles vem deixa o vírus aqui e vai embora.

A prefeitura tem que colocar FISCALIZAÇĀO competente rigorosa,mas tem medo de contrariar os poderosos.

Curtir-Responder - 8 sem
Estou bem feliz de ver q Tiradentes ainda continua sendo o cantinho do mundo $\mathrm{q}$ as pessoas escolheram pra descansar...economia voltando...não sou hipócrita de falar q não estou. Só acho q a fiscalização tá

falha...completamente falha! Curtir - Responder - 21 sem

\section{há meses}

muitos de nós

praticamente imploram

por investimento em

fiscalização do uso de

máscara, por parcerias com

forças de segurança. $O$

resultado tá aí, e inocentes

pagam, ou perdendo

renda, ou perdendo saúde.

Curtir-Responder - 6 sem
Prezado Prefeito,

Estive em Tiradentes, tenho residência aí, até 29/11/2020 e fiquei alarmado com o comportamento social tanto de moradores quanto, especialmente, dos turistas. Poucas pessoas usando máscaras, sem distanciamento social, e, o que achei pior, NÃO vi por parte das autoridades NENHUMA fiscalizaçăo ou cobrança do uso de máscaras. A situação da pandemia vem se agravando em todos os lugares e é necessário que as autoridades através dos seus agentes exijam o cumprimento das determinações da Prefeitura. Atenciosamente,

Curtir - Responder - 6 sem

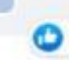

Fonte: Facebook - Perfil público da Prefeitura de Tiradentes (Tiradentes, 2020b). 
Essas manifestações populares reforçam a ineficácia e a contradição acerca da reabertura do turismo no município, inclusive em decorrência de discursos relativos a um suposto planejamento para o controle e contenção da Covid-19.

Hoje, nós temos uma equipe pronta e apta a detectar pacientes com Covid. Inclusive, criamos uma triagem em nossa Casa de Saúde para pacientes com suspeita de Covid. (...) compramos todos os EPIs pra todo pessoal da saúde que está no enfrentamento da Covid em Tiradentes. É! O que mais que eu posso falar disso? Tamo preparado! Inclusive, solicitei o exército também. Talvez a primeira cidade do Brasil que teve esse pensamento, né?! (PP8).

Todas as pousadas e restaurantes terão que seguir também uma rotina muito grande. Essa rotina seria a partir da entrada do hóspede no hotel pra um preenchimento de uma ficha de um check-in bem completa, aferição de temperatura, uso de álcool em gel em todas as áreas das pousadas, uso obrigatório de máscara por parte dos funcionários e por parte dos hóspedes, tá? (PP4).

Ademais, identificou-se que o resultado da falta de um planejamento sustentável efetivo refletiu, inclusive, na promulgação do DM 3.192, que dispunha de formas de contenção e restrição da entrada de turistas no município, ocasionado pelo aumento do número de visitantes com finalidades turísticas e pela propagação da Covid-19. Não tendo sido planejado para o retorno de algumas atividades, o município regrediu e progrediu as "Ondas" durante o ano 2020, conforme demonstram os DM 3.224, DM 3.318, DM 3.343, DM 3.347 e DM 3.357 na Tabela 4.

A partir dos excertos analisados através das reações populares em Tiradentes, tendo em vista, inclusive, os decretos expedidos e disponibilizados pelo site institucional da Prefeitura Municipal, dois aspectos devem ser ressaltados. Enquanto fatores de disseminação da Covid19, pode-se realçar os comportamentos dos turistas e dos próprios moradores locais. Em primeiro lugar, a controvérsia dos discursos proferidos, os quais não coadunam com o cenário real apresentado neste trabalho, pois as reações populares entre a população local apontam negativamente para a inércia de fiscalizações nos espaços públicos e privados quanto às medidas de segurança como o uso obrigatório de máscaras. Tal percepção indica que o comportamento dos turistas tenha acarretado a proliferação da doença. Fato este, também pode ser confirmado através da flexibilização do trade turístico, conforme DM 3.164. Este foi o primeiro sinal sobre a disseminação da Covid-19 em Tiradentes a partir do fluxo de turistas no território tiradentino, pois o município apresentou o primeiro caso confirmado da doença em 09.06.20, o qual também foi resultado do primeiro óbito. Na sequência, este estudo demonstrou que após a abertura definitiva da movimentação de turistas no município por meio do DM 3.203, a curva de contaminações pela Covid-19 mostrou-se ascendente.

Em segundo lugar, destaca-se o fraquejo demonstrado pela gestão pública, em especial o Poder Executivo Municipal, quanto à inabilidade sobre o controle e a salvaguarda às regras e protocolos estabelecidos para o enfrentamento da crise e reabertura do turismo. Os comportamentos dos cidadãos foram advertidos pelo PP6, ao se referir que a comunidade teria dificuldades em utilizar corretamente os EPIs e seguir corretamente com as medidas de segurança necessárias para a situação contingente. Considera-se que o comportamento inadequado dos turistas quanto às aglomerações e não uso das máscaras, pontuados pela 
população através do Facebook; a falta de fiscalização pelos órgãos públicos competentes; a inexperiência e a ausência de um controle instrucional constante com os moradores locais, sejam, entre as consequências socioeconômicas, os reflexos do cenário epidemiológico apresentado neste trabalho, com base no caso de estudo proposto.

\subsection{Fase de recuperação (4): Medidas são planejadas para a retomada do turismo visando ações e reflexões sobre o cenário pós-pandemia}

Essa fase "requer uma organização da sociedade para a reestruturação social e econômica do país. E, certamente, intervenção do Estado" (Werneck \& Carvalho, 2020: 2). Embora o contexto de pandemia da Covid-19 não tenha sido controlado ou encerrado até a finalização deste estudo, há questões relevantes e necessárias a serem discutidas nessa fase, ainda que o município de Tiradentes tenha tomado medidas que deveriam ser pertinentes para a Fase de Recuperação. Gladu (2003) assinala que a Recuperação refere-se às ações a serem executadas após uma crise. Isto posto, são aconselhadas medidas que visem o retorno às atividades turísticas em conformidade aos preceitos designados a indicadores de sustentabilidade (cf. Mediotte, 2020) no cenário de pós-pandemia.

Figura 6. Fase de recuperação - Tiradentes

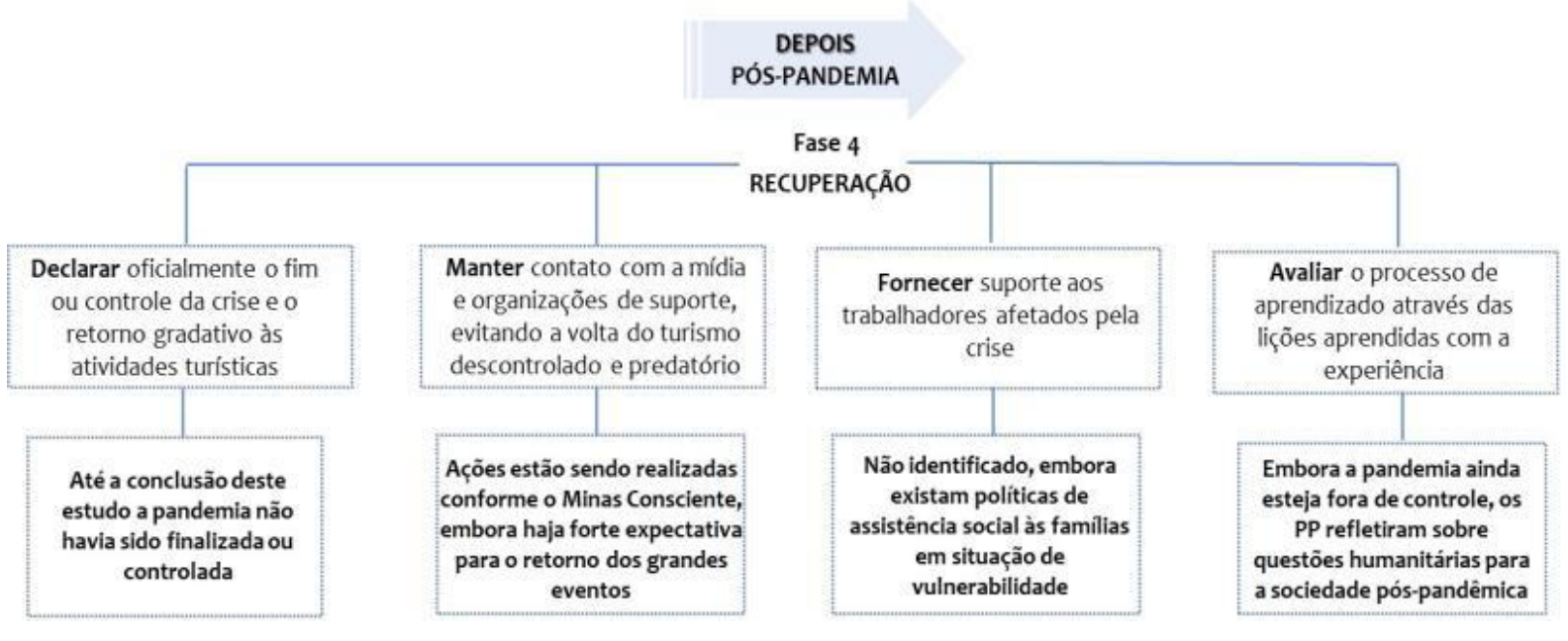

Mesmo não havido uma declaração oficial do município de Tiradentes quanto ao fim ou controle da pandemia, as atividades econômicas foram retomadas desde o dia 13 de julho de 2020, ainda que intermitentes, mesmo com a curva ascendente de casos confirmados pela Covid-19, conforme ilustrado no Gráfico 1.

Ao observar a evolução da Covid-19 no município de Tiradentes (Gráfico 1), dois pontos merecem destaque. $O$ primeiro refere-se ao crescimento da curva nos meses de novembro a dezembro de 2020. Entre os dias 27.11.20 a 18.12.2020, o município estava 'dentro' da “Onda” Amarela, conforme a Tabela 5 (versão 3.2 do Minas Consciente). Com a chegada das festas de Natal e Final de Ano em dezembro, houve um aumento na curva de casos confirmados da 
Covid-19, de 45 casos para 149 casos confirmados (até o dia 31.12.20), equivalente a 331\% de novembro a dezembro.

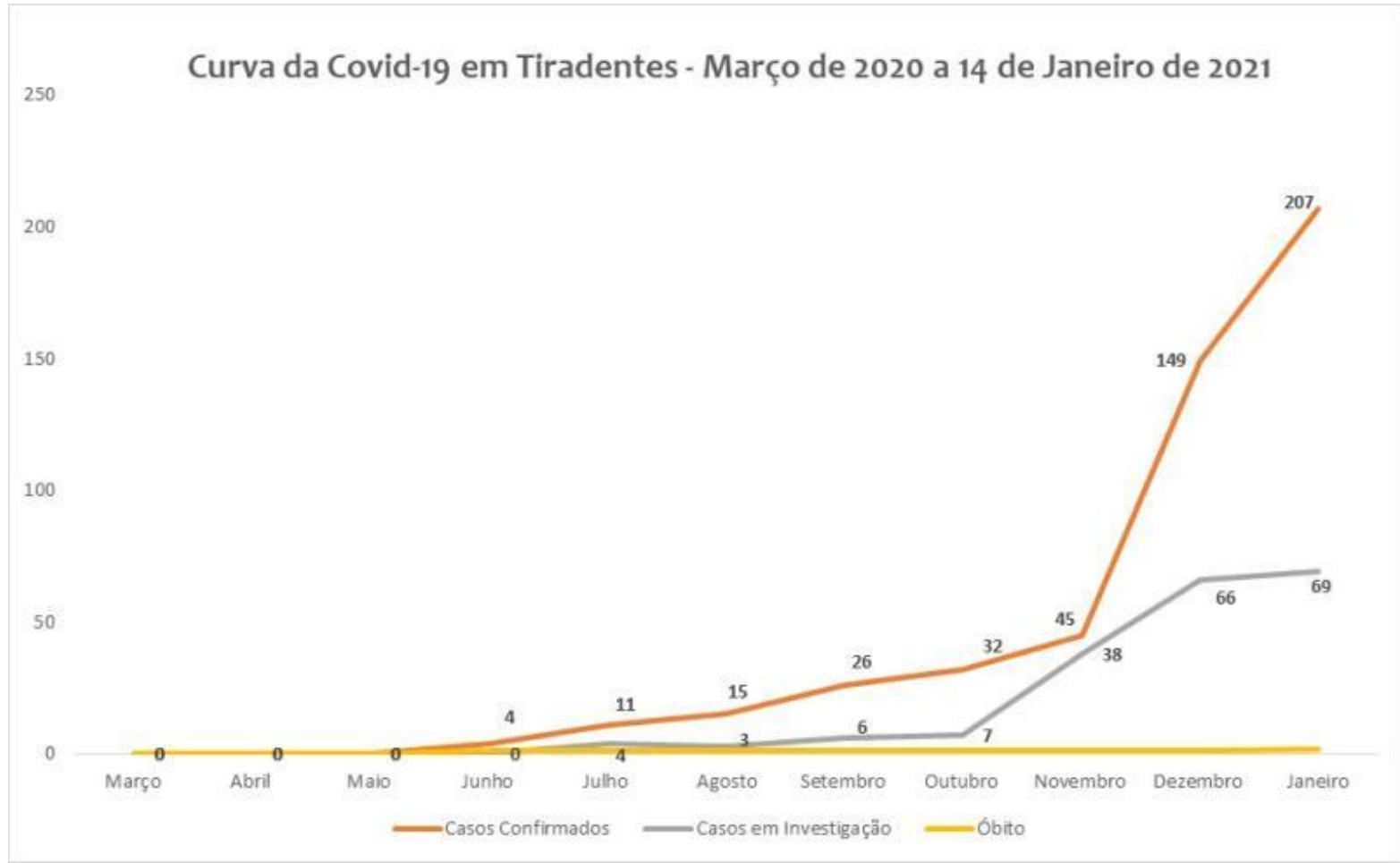

O segundo ponto refere-se ao DM 3.347, instituído pela Prefeitura de Tiradentes em 24.12.20, que autorizava, entre outras medidas, o funcionamento de lanchonetes e restaurantes para consumo local, com restrições de horário. Tal determinação estaria em dissonância com a "Onda" Vermelha, para a qual o município havia regredido desde o dia 18.12.20, conforme DM 3.343. Tal dispositivo fora revogado, por determinação judicial, de

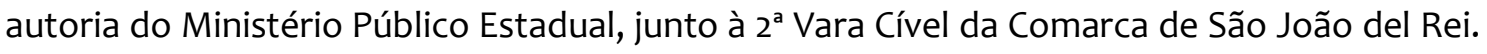
Portanto, o DM 3.357 passou a vigorar a partir de 31.12.20 (Tiradentes, 2020), o que pode-se inferir como causa de menor percentual de crescimento da curva, ainda que ascendente, comparado com o ocorrido entre os meses de novembro a dezembro de 2020.

Importante ressaltar que o PP3 e PP4 estimaram que no município haveria, até a data da finalização das entrevistas, mais de 2000 pessoas desempregadas, o que representa $25 \%$ da população total. Grande parte dos desempregados seriam os prestadores de serviços do trade turístico.

Além disso, quando questionados sobre as políticas assistenciais que o município estaria propondo para assistir aos desempregados, os PP1, PP3, PP4, PP5 e PP8 mencionaram a contemplação de cestas básicas e recargas de gás às famílias em vulnerabilidade econômica, além da já implementada ‘Bolsa Tiradentino', desde 2019.

Com base no período de realização da coleta de dados, até outubro de 2020 foram concedidas 257 cestas básicas e 67 recargas de gás. Até a data da segunda quinzena do mês de janeiro de 2021, horizonte temporal selecionado para a comparação dos Boletins Epidemiológicos locais, após o período de 14 dias de 'quarentena', o número de famílias 
contempladas somava, ao total, 867 cestas básicas e 136 recargas de gás, aumento de $337 \%$ e $202 \%$ respectivamente. Os dados são oriundos de contato telefônico informal com uma fonte interna à Prefeitura Municipal, resguardado o direito de confidencialidade, segundo o Art. $5^{\circ}$, XIV da Constituição Federal (CF), que dispõe do Livre Acesso à Informação e sigilo da fonte (Brasil, 1988/2017). Já o ‘Bolsa Tiradentino' é uma política criada em 2019 pela Administração Pública Local (2017-2020) que visa assistir 100 famílias vulneráveis socioeconomicamente, com o valor mensal de R\$100,00.

Por ser ano eleitoral para Representantes Locais (Prefeitos e Vereadores), não identificou-se DM liberados pelo, então, Poder Executivo Municipal, nos meses de agosto a outubro de 2020, no âmbito do enfrentamento da pandemia de Covid-19. O Tribunal Superior Eleitoral (TSE) estipulou o calendário para o sufrágio de 2020 e, de acordo com o cronograma, a partir do mês de agosto de 2020, iniciariam as coalisões e preparação para a escolha de representantes dos partidos aos cargos políticos, que, a partir de setembro, estariam liberados para realizar campanhas eleitorais. As datas relativas ao pleito de 2020 foram determinadas para os dias 15.11.20 (Primeiro Turno) e 29.11.20 (Segundo Turno) (Brasil, TSE, 2020).

Analisando as reações populares através do perfil aberto da Prefeitura Municipal de Tiradentes, pelo Facebook, os comentários sugerem que a possível ausência do Poder Executivo Local quanto às medidas de enfrentamento e acompanhamento da pandemia da Covid-19 ocorreram devido à campanha política para tentativa de reeleição ao cargo de Prefeito Municipal de Tiradentes.

Figura 7. Reações populares em Tiradentes - campanha política

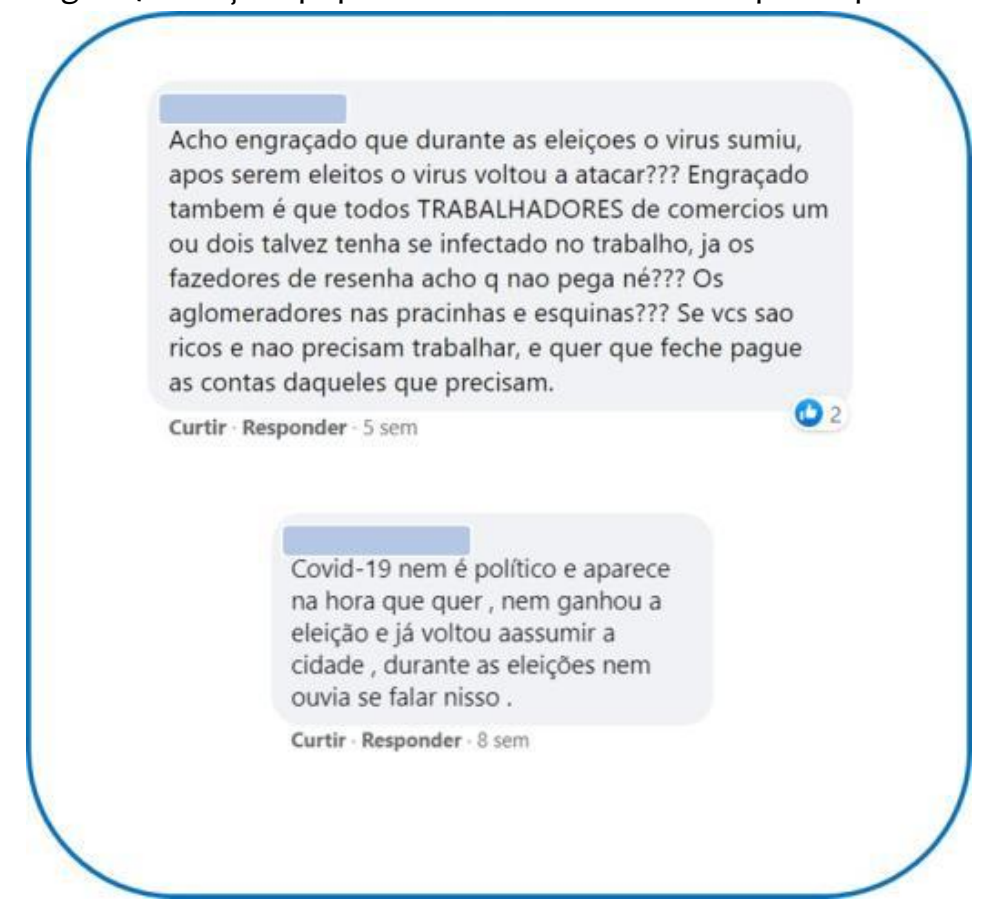

Fonte: Facebook - Perfil público da Prefeitura de Tiradentes (Tiradentes, 2020b). 
Com base no modus de gerenciamento de crises (re)adaptado neste estudo, embora a pandemia, até a conclusão da presente pesquisa, ainda esteja fora de controle em nível global, foi questionado aos PP quais as lições apreendidas, até então, com a experiência vivida pela pandemia da Covid-19. Feita a Análise de Conteúdo, por meio do software IRaMuTeQ 0.7 , foi originada a nuvem de palavras contendo os léxicos mais frequentes, os quais podem ser visualizados na Figura 8.

Figura 8. Nuvem de palavras - lições apreendidas com a pandemia da Covid-19

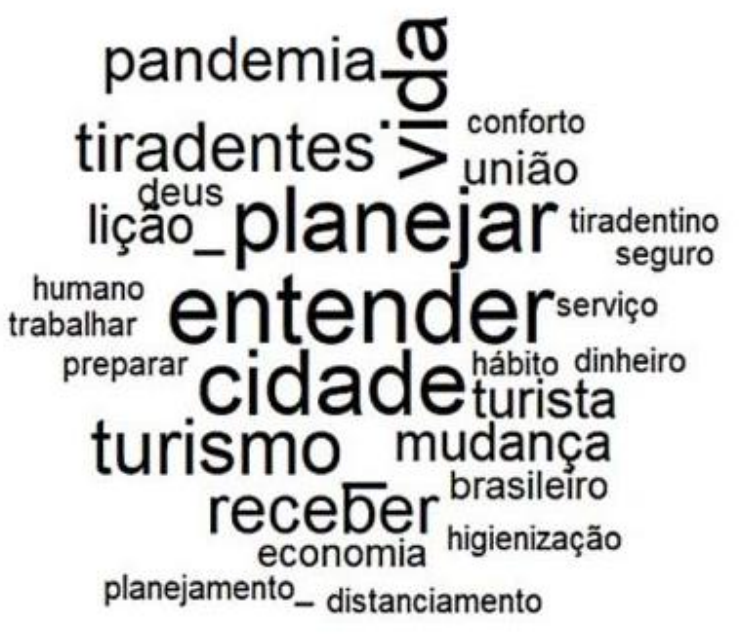

Fonte: Elaboração própria a partir do software IRaMuTeQ 0.7.

Diante o contexto analisado, e por se tratar de um fenômeno global, a pandemia da Covid-19, na percepção dos PP, revela distintas perspectivas. A palavra 'entender' aparece no centro da nuvem e, segundo as entrevistas, ela representa compreender que haverá mudanças no cenário de pós-pandemia, e que ações conjuntas deverão ser realizadas, pois, desde a recepção do turista, os cuidados com a saúde, física e mental, requerem uma compreensão de que o cuidado com o próximo será um diferencial nos destinos turísticos. A pandemia da Covid-19 tem servido de alerta, pois “o pessoal vai começar 'entender' como melhorar essa forma humana mesmo” (PP7). Além disso, perceber que será indispensável valorizar as tradições autóctones, os pequenos produtores.

(...) as pessoas têm que 'entender' que o turista não vem pra cá pra pegar trânsito de carro na rua e ficar tendo que buzinar. Ele vem pra cá por causa da tranquilidade que a cidade oferece, pela boa gastronomia, pelos monumentos bem cuidados. (...) Ele não vem aqui ‘pra' ver o Picasso, Da Vinci ou Dalí. Ele vem aqui ‘pra' ver o Seu Zé que tem aquela pintura bonitinha, que é legal, que é bacana (PP2).

A palavra 'planejar' também se faz constante na perspectiva dos PP que, apesar de não atuarem em prol de um planejamento que enfoque na sustentabilidade econômica, social, cultural, ambiental, ética e política, as suas reflexões se inclinam para um cenário póspandemia em consonância a um planejamento adequado e responsável para toda a indústria turística, no sentido de prevenção e ressocialização das interações locais e urbanas. Como disse o PP2, "E o que é que a gente tem que fazer? Vamos chamar um notório saber, um de 
cada área, da saúde, da educação... e vamos fazer uma semana de discussão. (...) Vamos ficar uma semana discutindo e dali sairiam as diretrizes pro futuro. Eu acho que tá na hora de fazer isso".

É nessa perspectiva que os seguintes Objetivos de Desenvolvimento Sustentável (ODS) da Agenda 2030 se fazem substanciais.

Figura 9. Objetivos de Desenvolvimento Sustentável da Agenda 2030 para destinos turísticos em uma sociedade pós-pandêmica

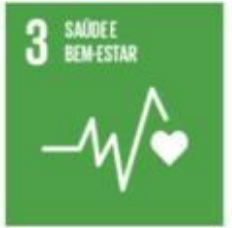

"ASSEGURAR UMA VIDA SAUDÁVEL E PROMOVER O BEM-ESTAR PARA TODOS, EM TODAS AS IDADES":

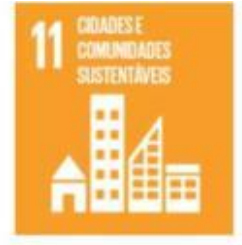

"TORNAR AS CIDADES E OS ASSENTAMENTOS HUMANOS INCLUSIVOS, SEGUROS, RESILIENTES E SUSTENTÁVEIS":

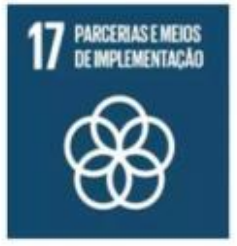

FORTALECER OS MEIOS DE IMPLEMENTACC̃OO E REVITALIZAR A PARCERIA GLÓBAL PARA 0 DESENVOLVIMENTO SUSTENTÁVEL

Fonte: Elaboração própria com base nos ODS da Organização das Nações Unidas (ONU, 2016).

A integração desses ODS visa somar esforços a partir da coparticipação de uma governança global que atenda às suas necessidades socioeconômicas, de forma sustentável (GTSCA2030, 2019). Dessa forma, tornando exequível que a retomada do turismo em destinos turísticos no cenário de pós-pandemia possa ocorrer de forma saudável, segura, inclusiva, resiliente e fortalecida por meio de parcerias que busquem erradicar o turismo descontrolado, sobretudo predatório (Irving et al., 2020).

O que se presenciou nesta pesquisa pode ser evidentemente mantido nas palavras de Huertas (1996: 12) ao revelar que "ou sabemos planejar, ou estamos condenados à improvisação". Além disso, torna-se eficaz a busca por novas parcerias, diálogos e concepções acerca da possibilidade de se reinventar o turismo. Desse modo, "o 'novo turista' (até aqui tão negligenciado em planejamento turístico), em termos de suas escolhas, passa a adquirir centralidade no debate" (Irving et al., 2020: 100).

Embora este estudo tenha revelado a inexistência de um planejamento público sustentável para o enfrentamento da crise epidemiológica causada pela pandemia da Covid19 em Tiradentes, relatam-se a presença de planos para desenvolver o município a longo prazo, como 'Projeto Educacional de Conscientização Infantil Desafio Tiradentes', que visa a instrução de crianças quanto à importância da conservação e preservação do patrimônio local; o 'Plano Diretor', que promove a participação municipal em assuntos acerca da otimização urbana. Há, ainda, dois outros planos em amadurecimento, como o 'Tiradentes Digital', que objetiva a inserção do município no mercado digital, a fim de conter a migração de jovens para outros municípios; 'Tiradentes Criativo', que propõe a adoção da economia criativa frente ao movimento feminista local, através das vocações culturais de mulheres em situação de vulnerabilidade (PP2, PP9). 
As questões humanas foram explicitamente percebidas por todos os PP que contribuíram com este estudo, haja vista que a pandemia trouxe essa problemática, muitas vezes latente ou preterida das ações de desenvolvimento do turismo. Sendo assim, recomenda-se aos destinos turísticos, em especial ao município em estudo, que a governança local se desloque do seu núcleo para que haja maior fomento em planejamento sustentável, em detrimento do crescimento exclusivamente econômico.

\section{Considerações finais}

Este estudo propôs um modus de gerenciamento para destinos turísticos em situações de crises. O contexto de pandemia da Covid-19 foi a problemática de análise e discussão dos dados e resultados obtidos. No entanto, acredita-se que a principal contribuição e originalidade do trabalho caracteriza-se não apenas na aplicação do modus de gerenciamento em situações de crises epidemiológicas, mas para todas as possíveis crises, que são imanentes a destinos turísticos.

Considera-se que o município de Tiradentes se antecipou de forma imprecisa para a retomada das atividades econômicas locais, a partir da adesão ao Plano estadual Minas Consciente. Portanto, as pressões do trade demonstraram-se ingrediente fulcral para a reabertura do turismo, sobretudo por haver um contrassenso ao reabrir o comércio local sem um contingente de testes para avaliar as possíveis fraquezas das medidas anteriormente empregadas, quando os sinais do surto da doença se mostravam evidentes, que o fez oscilar desde então.

Sem embargo, a comunidade civil, sem muitas opções, se vê impedida de atuar à frente das decisões e medidas deliberadas pela Core Governance. Tampouco se identificou, nos dados coletados, um planejamento público pré-pandemia, durante a pandemia e póspandemia, dotado de elementos sustentáveis para a retomada do turismo, no momento oportuno. O descontrole e a inaptidão da gestão pública frente aos anseios econômicos, a insuficiência de fiscalização quanto ao uso obrigatório de máscaras em espaços públicos e privados, a ineficácia quanto aos comportamentos da população local e dos turistas e às medidas restritivas de segurança, caminharam na contramão de um efetivo gerenciamento de crises, embora não se desconsidere que esforços foram depreendidos, os quais se mostraram inclinados ao viés exclusivamente econômico.

Os fatores limitantes desta pesquisa são teóricos e empíricos. Teóricos, devido à abordagem do tema proposto, especificamente no contexto de gestão de crises epidemiológicas em destinos turísticos e a escassez de literaturas consonantes. Por se tratar de um tema atual e vigente, empiricamente os fatores limitantes encontram-se no tempo para aprofundamento crítico para um cenário pós-pandêmico, nas restrições e adversidades relativas ao processo de entrevistas remotas, sem a presença in loco dos pesquisadores, sobretudo na indisponibilidade de acesso a documentos públicos atualizados, conforme supradito.

O caso de Tiradentes pode ser estendido para outros destinos turísticos. De forma imediata, considerando que uma sociedade pós-pandêmica possa tornar os espaços urbanos em potenciais fomentadores de potencialidades criativas, onde ocorrerão interações humanas em conciliação com ações mais democráticas, este estudo reafirma a necessidade de se construir parcerias público-privadas e entre pessoas, em âmbito multinível, para que 
novas ideias, rumos, soluções e gestão qualificada possam ser postos em prática, em especial, para a dinâmica do turismo, que requer, sobremaneira, renovação e sustentabilidade econômica, cultural, ambiental, política e ética, preservando a qualidade de vida e o bem-estar social.

Em suma, acredita-se que os benefícios desta pesquisa possam trazer insumos relevantes para a academia, para as Instâncias Municipais de turismo envolvidas com o enfrentamento da pandemia causada pela Covid-19, e, para a comunidade civil que atua ou depende do turismo. Além disso, para os participantes da pesquisa, que gentilmente cederam momentos preciosos para a construção deste estudo, em um momento tão conturbado, que tem sido a pandemia da Covid-19. Assim, espera-se que esta pesquisa possa contribuir para o avanço no conhecimento da complexidade das relações entre a governança local, o gerenciamento de crises e o planejamento público para o desenvolvimento turístico sustentável em situações de crises.

\section{Referências}

Bardin, L. (2014). Análise de conteúdo. (5ªd). Edições 70.

Brasil, Constituição de 1988 (CF/88). (2017). Constituição da República Federativa do Brasil. Brasília, Coordenação de Edições Técnicas.

Brasil, Ministério do Turismo (MTur). (2015). Índice de Competitividade do Turismo Nacional: Relatório Brasil. Brasília.

Brasil, Ministério do Turismo (MTur) (2019). Categorização dos Municípios das Regiões Turísticas do Mapa do Turismo Brasileiro. Brasília.

Brasil, Ministério do Turismo (MTur) (2020). Mapa do Turismo 2017-2019. Brasília.

Brasil, Presidência da República (Casa Civil) (2011). Lei de Acesso à Informação (Lei № 12.527/11).

Brasil, Tribunal Superior Eleitoral (TSE) (2020). Calendário Eleitoral - Eleições. Brasília.

Cooper, M. (2008). Japanese tourism and the SARS epidemic of 2003. Journal of Travel \& Tourism Marketing, 19(2-3), 117-131. https://doi.org/10.1300/J073v19n02_10

Croda, J., Oliveira, W. K., Frutuoso, R. L., Mandetta, L. H., Baia-da-Silva, D., Brito-Sousa, J., Monteiro, W. \& Lacerda, M. V. (2020). COVID-19 in Brazil: Advantages of a socialized unified health system and preparation to contain cases. Journal of the Brazilian Society of Tropical Medicine, (53), 1-6. https://doi.org/10.1590/0037-8682-0167-2020

Dallabrida, V. R. (2016). Ativos territoriais, estratégias de desenvolvimento e governança territorial: uma análise comparada de experiências brasileiras e portuguesas. EURE, 42(126), 187-212.

Flaxman, S. et al. (2020). Report 13: Estimating the number of infections and the impact of nonpharmaceutical interventions on COVID-19 in 11 European countries. Imperial College COVID-19 Response Team, 1-35. https://doi.org/10.25561/77731

Gladu, A. (2003). Crisis and emergency management: A guide for managers of the public service of Canada. Ottawa: CCMD.

GTSCA2030 - Grupo de Trabalho da Sociedade Civil para a Agenda 2030 (2019). III Relatório Luz da Sociedade Civil da Agenda 2030 para o Desenvolvimento Sustentável. Recife.

Huertas, F. (1996). O método PES: Entrevista com Matus. FUNDAP.

Inskeep, E. (1993). National and Regional Planning, Methodologies and Case Studies. Routledge.

IBGE - Instituto Brasileiro de Geografia e Estatística (2018). PIB por Município: Tiradentes. 
IBGE - Instituto Brasileiro de Geografia e Estatística (2020). Tiradentes: Panorama.

IPHAN - Instituto do Patrimônio Histórico e Artístico Nacional (2020). Tiradentes (MG). Brasília.

Irving, M. A., Coelho, A. M. \& Arruda, T. O. (2020). Turismos, sustentabilidades e pandemias: Incertezas e caminhos possíveis para planejamento turístico no horizonte da Agenda 2030. Observatório de Inovação do Turismo, 14, 73-105.

Johns Hopkins University (2020). COVID-19 Dashboard by the Center for Systems Science and Engineering (CSSE) at Johns Hopkins University (JHU). Baltimore.

Kuo, H., Chen, C. C., Tseng, W. C., Ju, L. F., \& Huang, B. W. (2008). Assessing impacts of SARS and Avian Flu on international tourism demand to Asia. Tourism Management, 29(5), 917-928. https://doi.org/10.1016/j.tourman.2007.10.006

Lam, W., Zhong, N., \& Tan, W. (2003). Overview on SARS in Asia and the world. Respirology, 8, S2-S5.

McKercher, B. \& Chon, K. (2004). The over-reaction to SARS and the collapse of Asian tourism. Annals of Tourism Research, 31(3), 716-719. https://doi.org/10.1016/j.annals.2003.11.002

Mediotte, E. J. (2020). Avaliação da Governança em Instância Deliberativas Coletivas e sua relação com o Planejamento Turístico no município de Tiradentes (MG). Dissertação de Mestrado, Universidade Federal de Viçosa, Brasil.

Minas Gerais, Cidade Administrativa. (2020). Plano Minas Consciente: retomando a economia do jeito certo. Belo Horizonte.

Minayo, M. C. S. (Org.). et al. (2011). Pesquisa social: Teoria, método e criatividade. (30 ed). Vozes.

Niestadt, M. (2020). Covid-19 and the tourism sector. European Parliamentary Research Service (EPRS), 1-2.

ONU - Organização das Nações Unidas (ONU Brasil). (2016). Transformando nosso mundo: a Agenda 2030 para o Desenvolvimento Sustentável. Brasília.

OPAS - Organização Pan-Americana de Saúde (2020). Folha informativa - Covid-19 (doença causada pelo novo coronavírus). Brasília.

Paraskevas, A., Altinay, L., McLane, J. \& Cooper, C. (2013). Crisis knowledge in tourism: Types, flows and governance. Annals of Tourism Research, 41 (2), 130-152. https://doi.org/10.1016/j.annals.2012.12.005

Pardal, L. \& Correia, E. (1995). Métodos e técnicas de investigação Social. Areal.

Ruschmann, D. V. M. (1997). Turismo e planejamento sustentável: A proteção do meio ambiente. (16 ed). Papirus.

Sá-Silva, J. R., Almeida, C. D. \& Guindani, J. F. (2009). Pesquisa documental: Pistas teóricas e metodológicas. Revista Brasileira de História \& Ciências Sociais, 1(1), 1-15.

Santos, T. S., \& Pereira, R. S. (2020). O turismo como impulsionador do desenvolvimento regional: Análise no Campo das Vertentes (MG), Brasil. EURE, 46(137), 113-133. http://dx.doi.org/10.4067/S0250-71612020000100113

SENAC - Serviço Nacional de Aprendizagem Comercial (2020). Descubra Minas.

Tiradentes, Prefeitura Municipal (2020a). Decretos Municipais.

Tiradentes, Prefeitura Municipal (2020b). Perfil Aberto do Feed de Notícias do Facebook.

Tiradentes, Prefeitura Municipal (2020c). Reunião do Comitê Gestor Covid-19 com Empresários e Comerciantes Locais.

Trentin, F. (2016). Governança turística em destinos brasileiros: comparação entre Armação dos Búzios/RJ, Paraty/RJ e Bonito/MS. Revista de Turismo y Patrimonio Cultural (PASOS), 14(3), 645658.

Triviños, A. N. S. (1987). Introdução à pesquisa em ciências sociais: a pesquisa qualitativa em educação. Atlas.

UNWTO - World Tourism Organization (2020a). 2020: A year in review. UNWTO. 
UNWTO - World Tourism Organization (2020b). Tourism back to 1990 levels as arrivals fall by more than 70\%. UNWTO.

Werneck, G. L., \& Carvalho, M. S. (2020). A pandemia de COVID-19 no Brasil: crônica de uma crise sanitária anunciada. Cad. Saúde Pública, 36(5), 1-4. https://doi.org/10.1590/0102-311X00068820

Wilder-Smith, A. (2006). The severe acute respiratory syndrome: Impact on travel and tourism. Travel Med. Infect. Dis., 4(2), 53-60. https://doi.org/10.1016/j.tmaid.2005.04.004

World Bank (2020). COVID-19 to Plunge Global Economy into Worst Recession since World War II. Washington, D.C.

WHO - World Health Organization (2020). Global surveillance for COVID-19 caused by human infection with COVID-19 virus. Genebra.

Yamaoka, E. J. (2009). O uso da internet. In J. Duarte \& Barros, A. (Eds.), Métodos e técnicas de pesquisa em comunicação. ( $2^{\mathrm{a} e d}$.) (pp.146-162). Atlas.

Agradecimentos: Ao Conselho Nacional de Desenvolvimento Científico e Tecnológico do Brasil (CNPq Processos 310574 / 2016-1; 309363 / 2019-5), à Fundação de Pesquisa de Minas Gerais (FAPEMIG - Processos APQ-01870-15; PPM-00049-18) e à Coordenação para o Aperfeiçoamento de Pessoal de Nível Superior (CAPES - Financiamento 001), Ministério da Educação, Brasil. Agradecimentos adicionais à equipe editorial e avaliadores anônimos pelas suas valiosas contribuições que repercutiram positivamente no presente artigo.

EliAs JosÉ Mediotte é doutorando e mestre em Administração Pública pela Universidade Federal de Viçosa (UFV), Brasil. Membro e Pesquisador do Grupo de Pesquisa em Gestão e Desenvolvimento de Territórios Criativos (GDTeC); Grupo de Pesquisa em Administração e Análise de Políticas Públicas (GPeAPP), da UFV; Grupo de Pesquisa Observatório de Estudos de Turismo e Desenvolvimento (OBSERVATUR), da EACH-USP. Desempenha e tem interesse em pesquisas que abarcam os temas: Governança, Planejamento e Desenvolvimento Sustentável, Gestão e Políticas Públicas de Turismo, Economia Criativa, Placemaking, Cidades Criativas. Endereço Institucional: Departamento de Administração e Contabilidade, Universidade Federal de Viçosa, Viçosa, 36570-900, Brasil.

Magnus luiz Emmendoerfer é professor associado do Programa de Pós-Graduação em Administração Pública, Universidade Federal de Viçosa, Brasil. Doutor em Ciências Humanas: Sociologia e Políticas pela Universidade Federal de Minas Gerais, Brasil. Administrador e Mestre em Administração pela Universidade Federal de Santa Catarina, Brasil. Líder do Grupo de Pesquisa em Gestão e Desenvolvimento de Territórios Criativos (GDTeC), da UFV. Desempenha e tem interesse em pesquisas que abarcam os temas: Gestão e Políticas Públicas de Turismo, Economia Criativa, Sustentabilidade, Governança, Inovação e Empreendedorismo no Setor Público, Métodos Qualitativos e Casos Para Ensino em Administração Pública e Gestão Social, Estratégias Didáticas. Endereço Institucional: Departamento de Administração e Contabilidade, Universidade Federal de Viçosa, Viçosa, 36570-900, Brasil.

YURI Tomaz dos Santos é graduando em Comunicação Social, com ênfase no Jornalismo, pela Universidade Federal de Viçosa, Brasil. Membro do Grupo de Pesquisa em Gestão e Desenvolvimento de Territórios Criativos (GDTeC), da UFV; Grupo de Pesquisa Observatório de Estudos de Turismo e Desenvolvimento (OBSERVATUR), da EACH-USP. Bolsista de Iniciação Científica (PIBIC), pesquisando 
o seguinte tema: Governança no Turismo e Cidades Criativas da UNESCO, regida e financiada pelo Conselho Nacional de Desenvolvimento Científico e Tecnológico - CNPq. Endereço Institucional: Departamento de Administração e Contabilidade, Universidade Federal de Viçosa, Viçosa, 36570-900, Brasil.

Brendow de Oliveira Fraga é professor substituto da Universidade Federal de Viçosa e professor efetivo da Faculdade do Futuro, Brasil. Doutorando e Mestre em Administração Pública pela Universidade Federal de Viçosa (UFV), Brasil. Membro do Grupo de Pesquisas em Gestão e Desenvolvimento de Territórios Criativos (GDTeC), da UFV. Desempenha e tem interesse em pesquisas que abarcam os temas: Gestão Pública do Turismo e da Cultura, Coprodução de Bens e Serviços Públicos e Desenvolvimento local. Endereço Institucional: Departamento de Administração e Contabilidade, Universidade Federal de Viçosa, Viçosa, 36570-900, Brasil.

Submetido em 31 de janeiro 2021

Aceite em 4 de abril 2021 